\title{
استخدامات العلاقات العامة الرقمية في عمل الجامعات العراقية دراسة مسحية للعاملين في العلاقات العامة
}

د. صباح انور محمد

الجامعة العراقية - كلية الإعلام

\section{المستخلص}

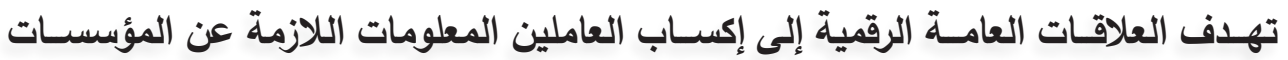

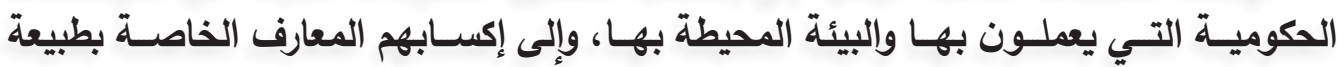

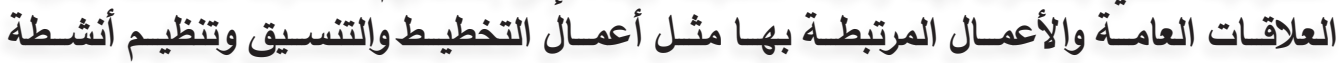

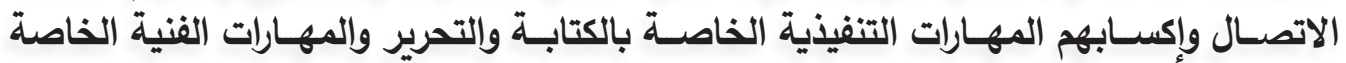

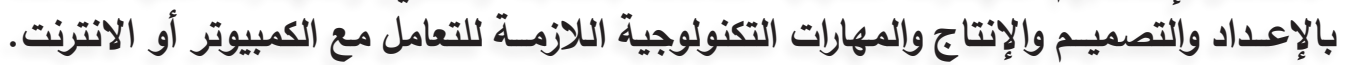

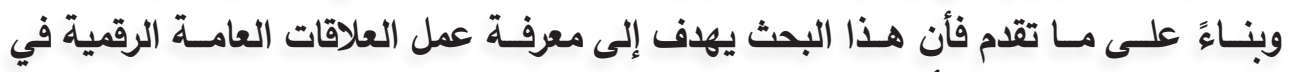

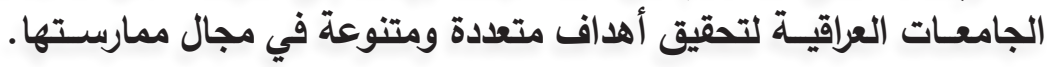
وتضمنت مشكلة البحث تساؤلات عدة، منها :

ا ـ مـا الاسـتخدامات والاثـباعات المتحققة نتيجة اسـتخدام العاملين للعلاقـات العامة الرقمية

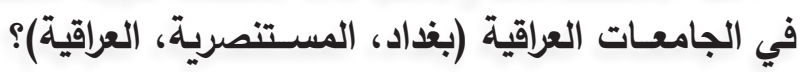
r. ما آليات تطبيق العلاقات العامة الرقمية للاتصال التفاعلي في الجامعات العراقية؟ المعاهيه

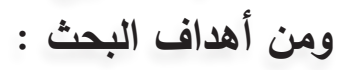

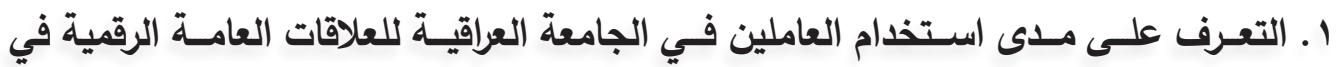

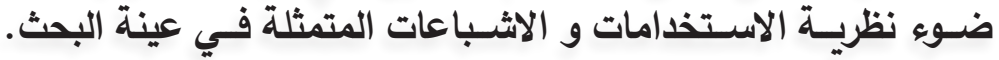

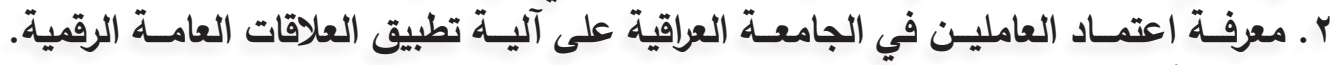

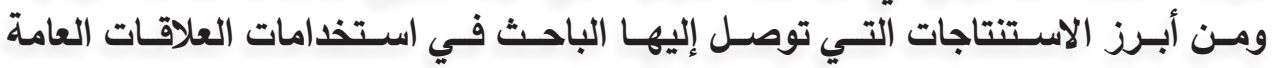

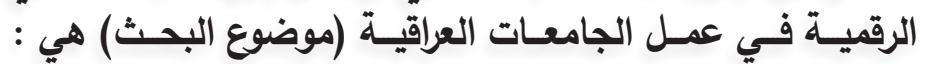

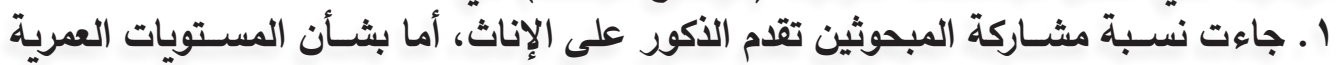

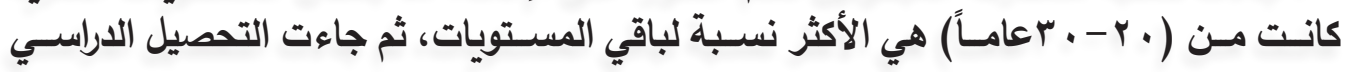

\section{Sabah67anwar@gmail.com}

\begin{tabular}{l|c} 
& العلة الباحث الإعلامي \\
\hline IV & (rv (rv
\end{tabular}


(شـهادة البكالوريـوس) الأكثر مشـاركة، ثم جـاءت مكان العمل جامعة بغـداد بالمرتبة الأولى

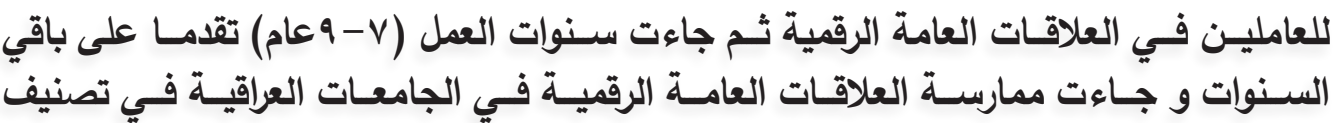
مسـتفيد (نعن) بالمرتبـة الأولى.

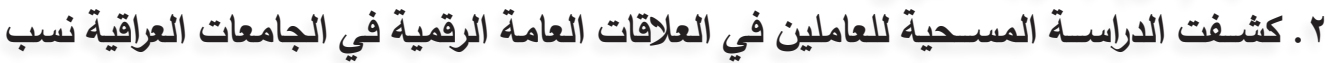

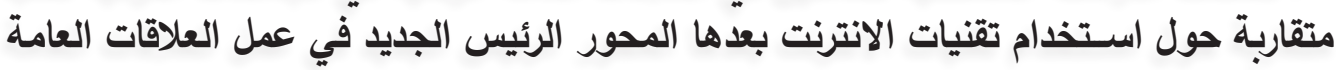
الرقمية بينما كانت الإجابة الأضعف هي عدم استخدام تقنيات الانترنت في مجال العلاقات العات العامة.

\section{The Use of Digital Public - Relations in the Work of Iraqi Universities}

A Survey Study of the Workers in the Departments of Public Relations

the digital public relations aim at make the workers getting the necessary information about the governmental institutions where they work and the enveronmentsurroundingthem.italsotriestolettheworkersgetthespecialknowlege oftthepublich relationsand theirjobsliketheworksofplanning, arranging theactive communication and executive skills needed in their writing, editing, special art skills for designing, production and technological skills to deal with the computer.

the problem of the research includes some questions as :

1- what are the uses achieved by degetal public relations workers at Iraqi universities (Baghdad, Mustansiriya, and Iraqi)

2 - what are the tools used to apply digital public relations in active communication at Iraqi universitites?

The goals of the research are as follows:

Identifying the extent to which employees use digital public relations according to the theory of uses and saturation .

identifying the extent to which employees' dependence on the tool of applying digital public relations

the researcher ends with the following conclusions:

1- the number of male respondents are larger than the females. their age is abut $\mathbf{2 0}$ years up to $\mathbf{3 0}$ years old . the educational level of the respondents who have bahelor degree are larger than those who have higher degrees. The university of Baghdad is higher in the number of workers in the departments of digital public relaions.

2- the number of those who know how to use the internet and computer

\begin{tabular}{l|c} 
& مجلة الباحث الإعلامي \\
\hline$\Upsilon \Lambda$ & العدد (TV
\end{tabular}




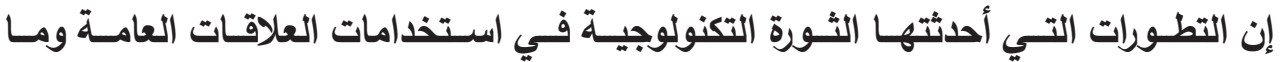

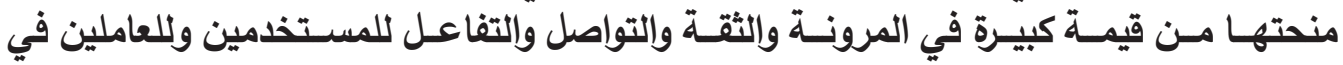

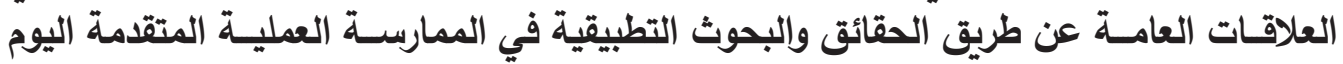

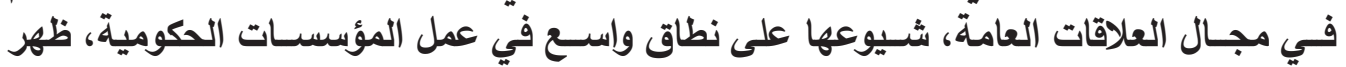

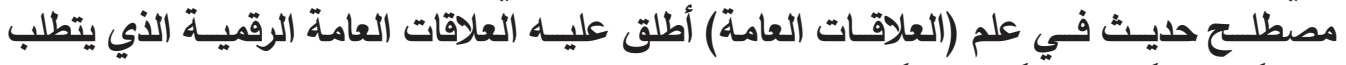

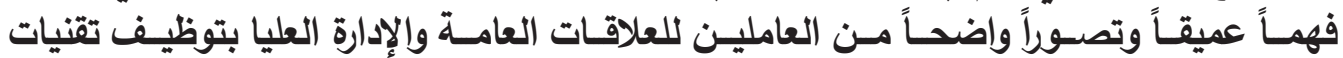

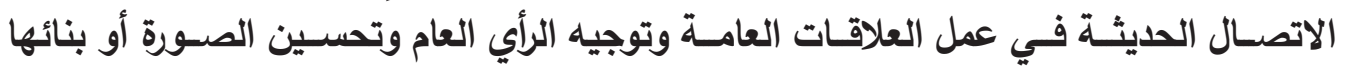

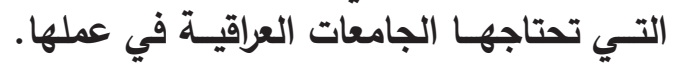

قـــ الباحـث بحثـه على ثلاثة مباحثث وقد تناول المبحـث الأول منه : الإطـار المنهجي

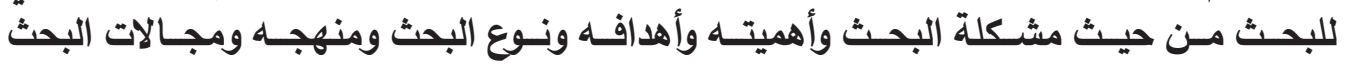

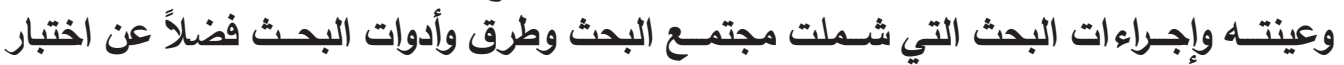

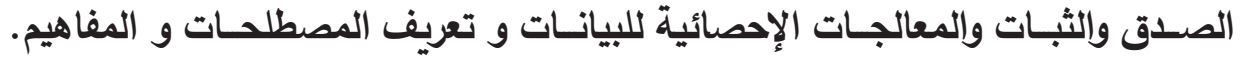
أمـا المبحث الثانـي : فقد تــاول الباحث فيه : مفهـوم العلاقات العامــة الرقمية ووظائفها

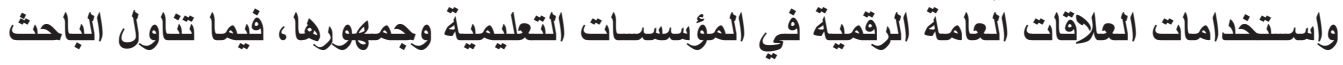

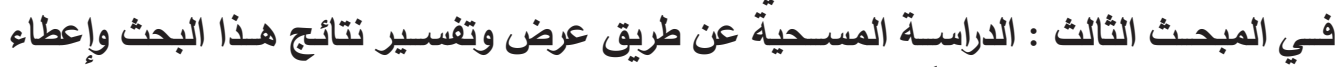

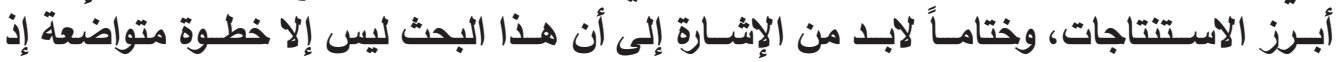

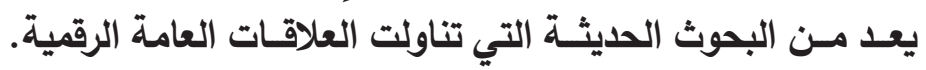
الإطار المنهجي للبحث أولاً : مشكلة البحث البن

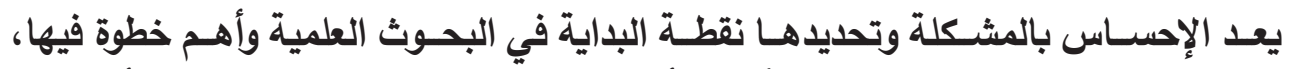

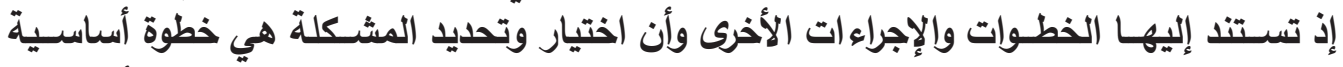

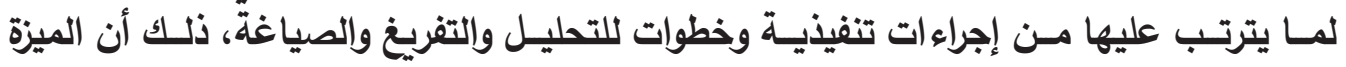

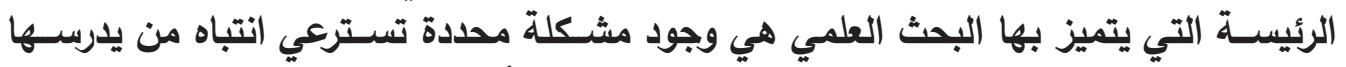

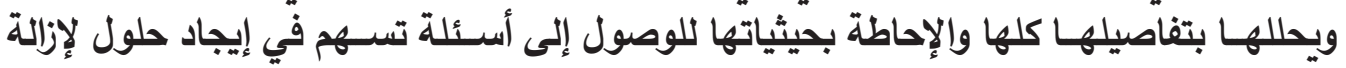

ذلك الغمـوض والتحقق منه.(1)

ويمكـن تحديد مشـكلة بحثنا بالتعـرف على العلاقات العامة الرقميـة بصفتها مفهوماً حديثاً

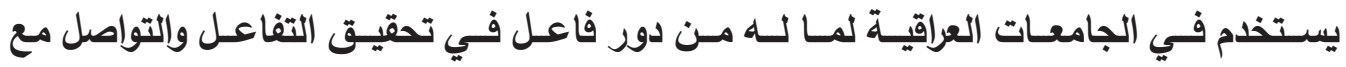

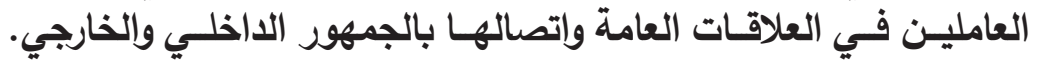




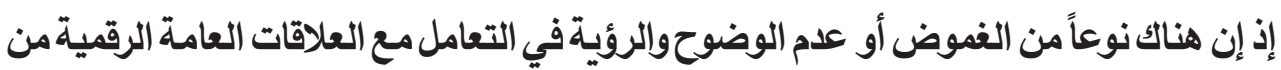
حيث استخدامات العاملين بها في الجامعات العراقية ويمكن إيجاز مشكلة البحث بالتوفي التساؤلات الآتية :

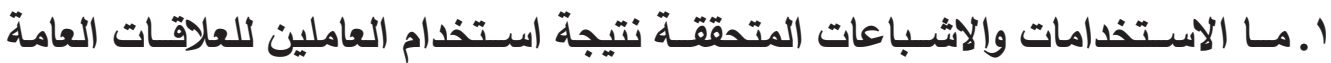

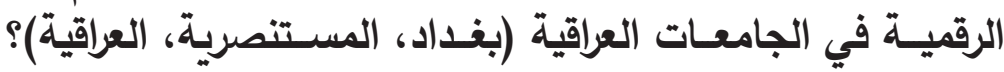

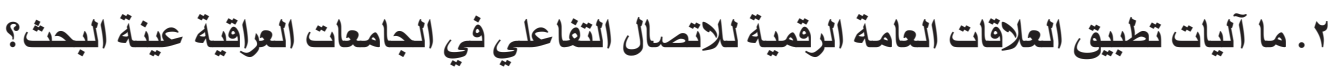

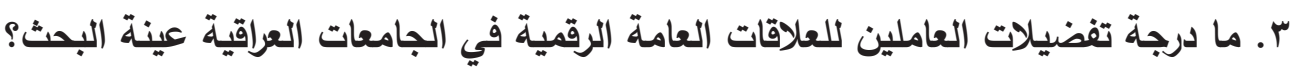

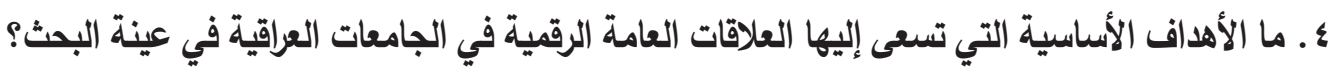

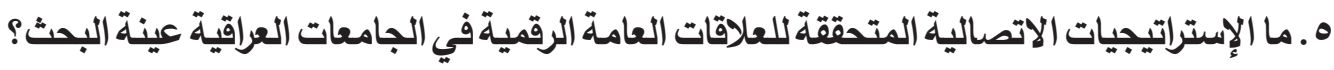

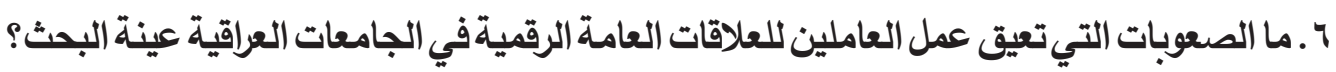
ثانياً : أهمية البحث

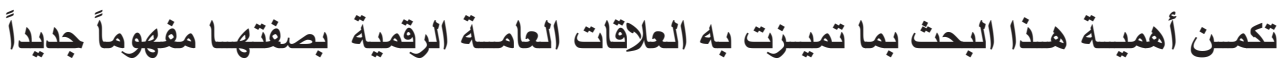

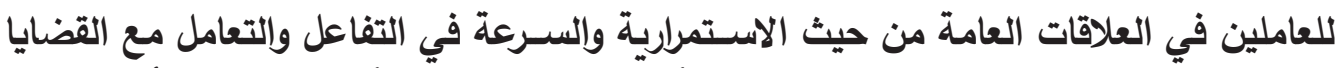

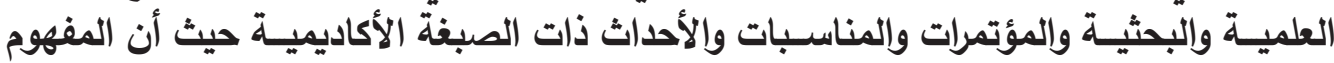

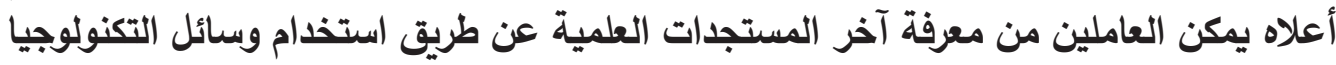

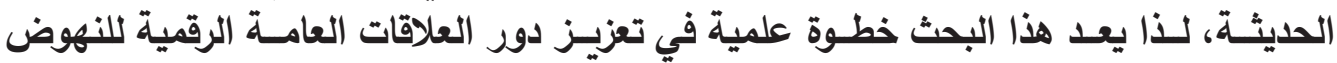

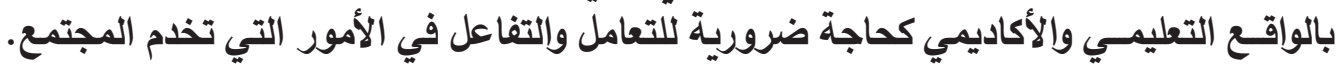
ثالثاً : أهداف البحث

تعـد أهداف البحث العلمي مؤثـرات أساسـية يتوصل إليها الباحث عـن طريق النتائج التي

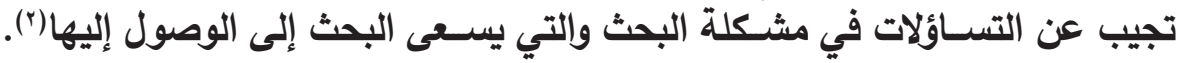

$$
\text { ويرمي هذا البحث إلى ما يأتي : }
$$

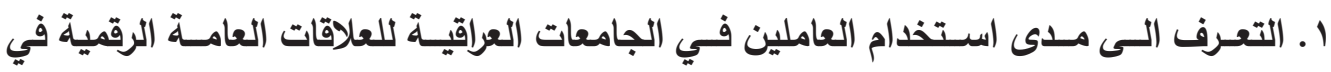

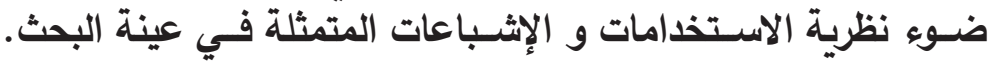
r ـ معرفـة اعتمـاد العامليـن في الجامعـات العراقية على آلية تطبيق العلاقـات العامة الرقاتهات الرقمية.

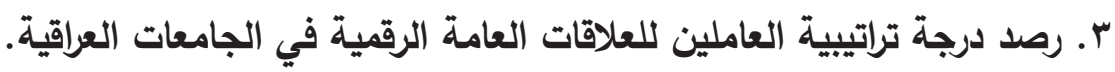

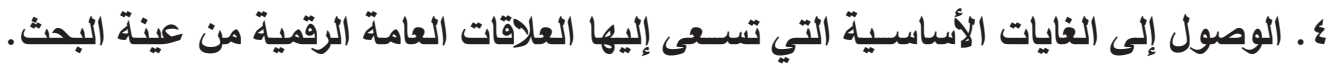
هـ الوقوف إلى سترايجيات الاتصال المتحققة للعلاقات العامة الرقمية. צ. تحديــ المعوقـات التـي تعيق عمل العاملين للعلاقات العامـة الرقمية في الجامعات العراقية.

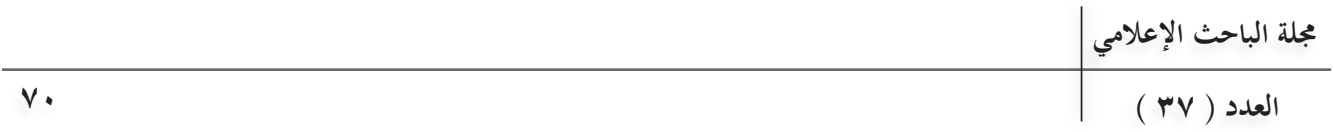




\section{رابعاً : منهج البحث ونوعه}

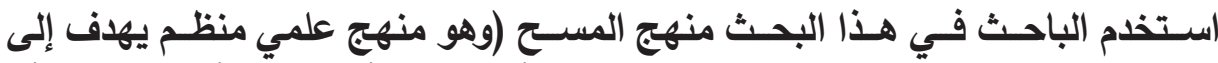

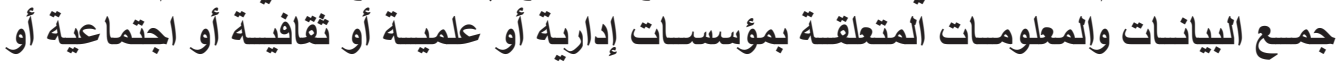

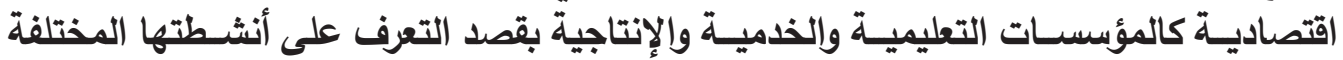

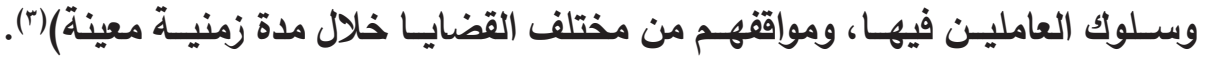

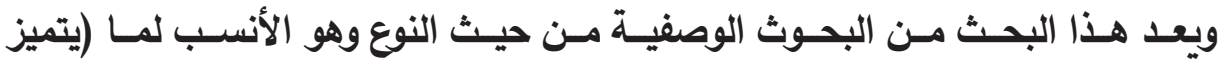

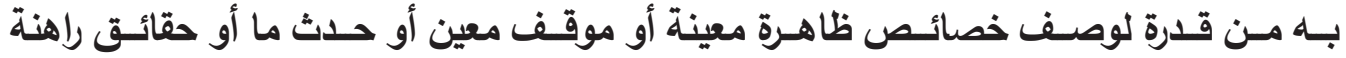

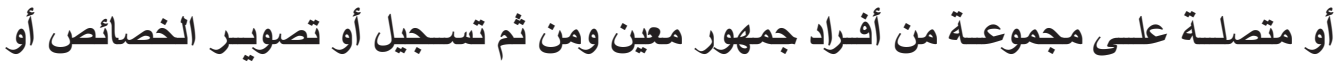

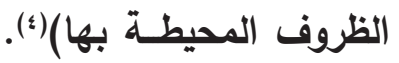

وعن طريق هذا المنهج يمكن معرفة استخدامات العلاقات العامة الرقمية في الجامعات العراقية.

\section{خامساً : مجالات البحث}

ا ـ المجـال المكانسي : تمثل بالجامعـات العراقية (بغداد، المسـتنصرية، العراقية) مجالاً مكانياً

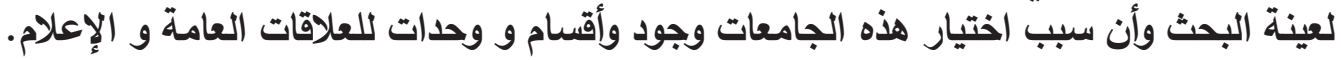

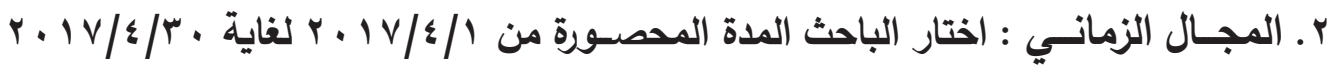

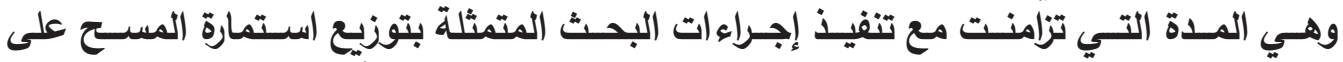

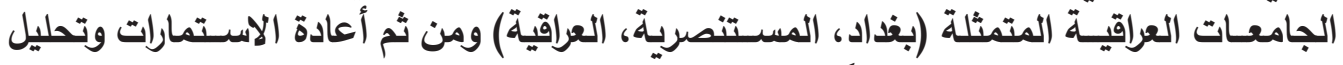
بياناتها لغـرض معالجتها إحصائياً.

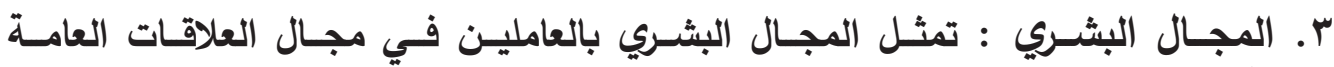

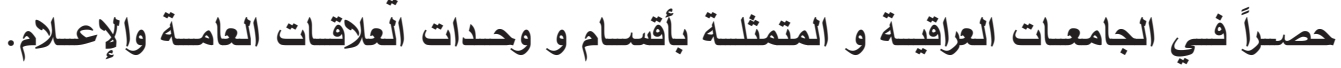

\section{سادساً : عينة البحث}

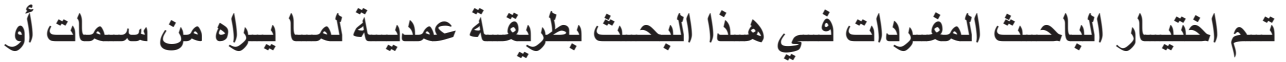

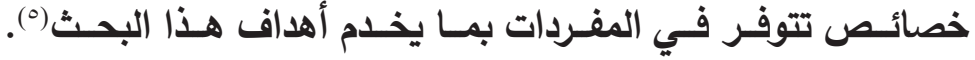

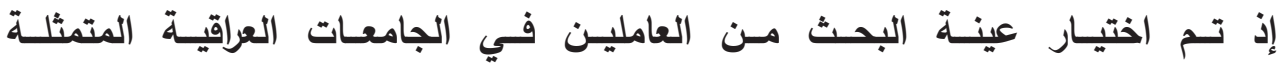

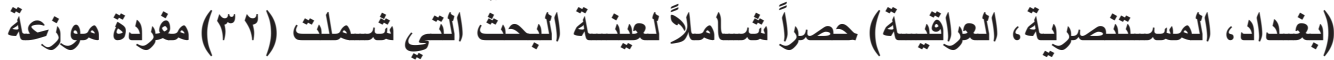

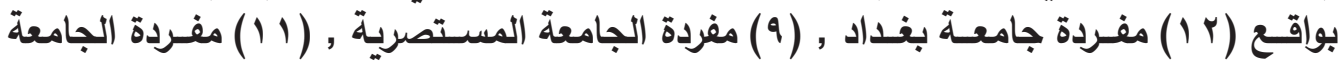

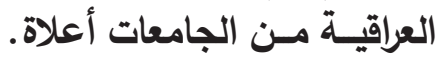




\section{سابعاً : إجراءات البحث

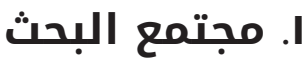

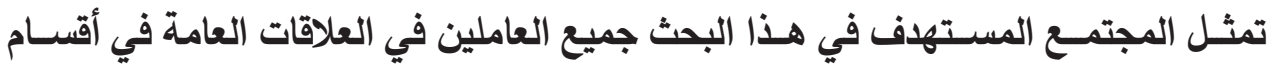

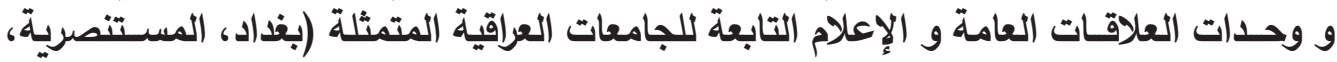

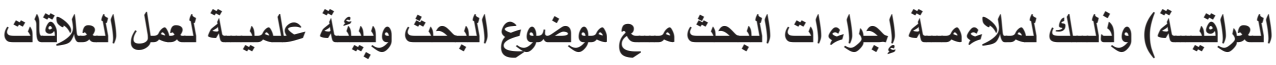

العامـة الرقمية في الجامعات العراقية.

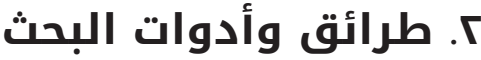

اسـتخدم الباحـث في هذا البحث مجموعـة من الأدوات للوصول إلـى البيانات والمعلومات

المتعلقة بموضسوع البحث وكالآتي:

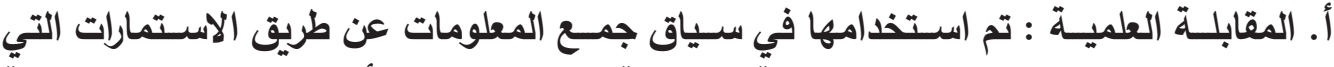

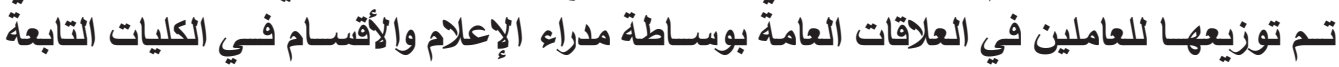
للجامعات العراقيـة موضوع البحث. تلعين

ب. اسـتبانة المسـح : وتكونـت مـن شـقين رئيسيين (المعلومات العامة وأسـئلة الاسـتبانة)

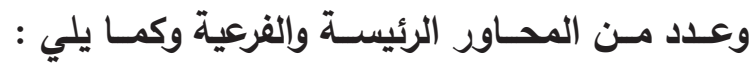

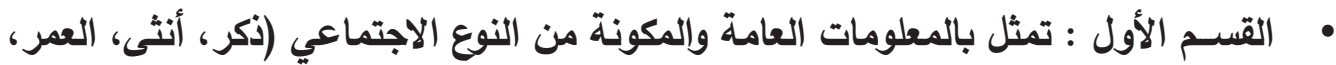

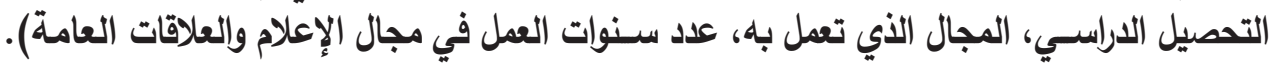
• • القسم الثاني : الأني شمل أسئلة الاستبانة والتي تتمثل بالمحاور الآتية :

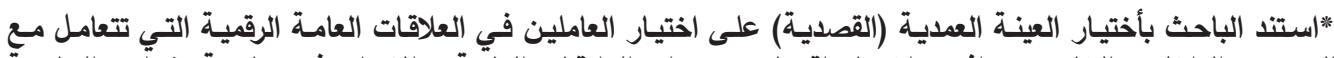

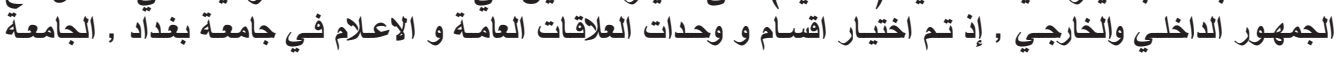
المتتصرية , الجامعة العرقيـة.

- المحور الأول : استخدامات العلاقات العامة الرقمية في الجامعات العرقية. - المحور الثاني : تطبيق العلاقات العامة الرقمية في الجامعات العات العات العاقية. العاتية.

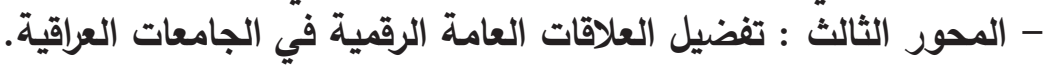

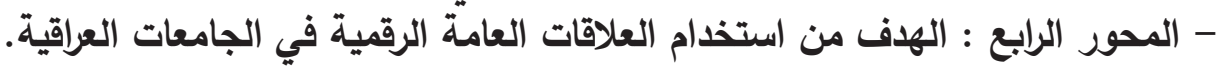

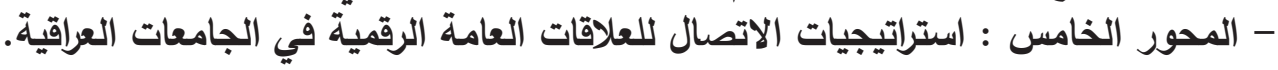
- الدحور السادس : الصعوبات التي تعيق عمل العلاقات العامة الرقمية في الجامعات العرقية العاتية.

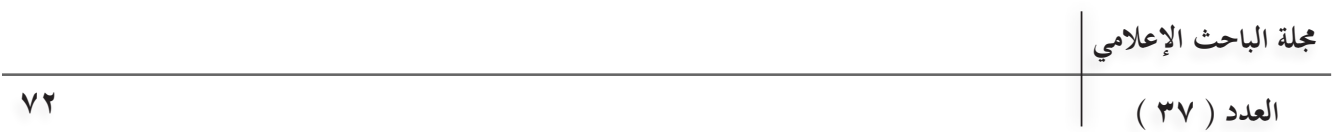




\section{ثامناً : الصدق والثبات}

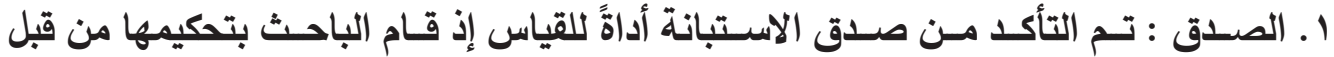

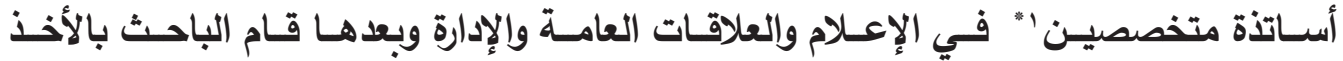

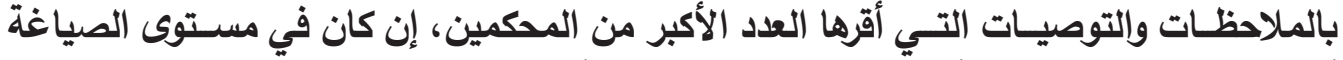

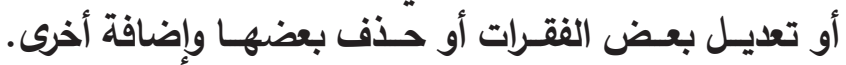

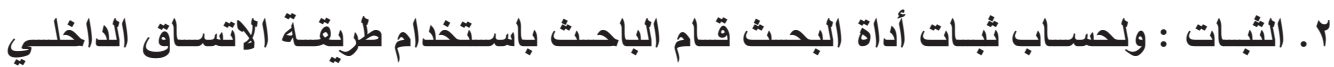

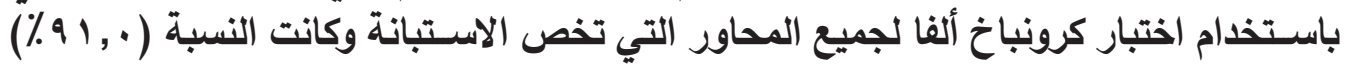

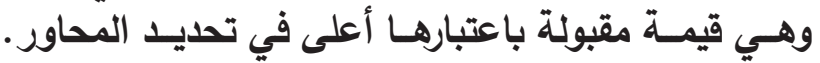

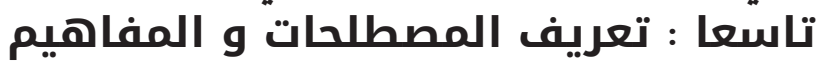
• العلاقـات العامــة :- هـي الجهود المقصودة و المســمرة و المخططة التـي تقوم بها ادارة

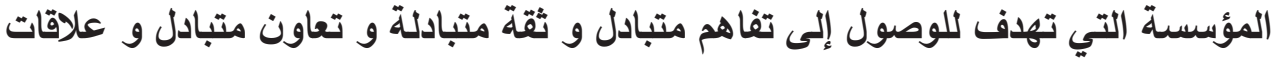

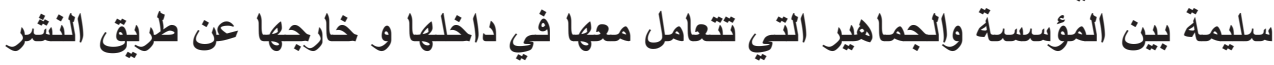

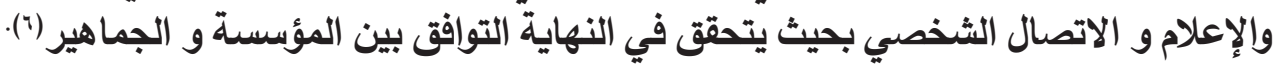

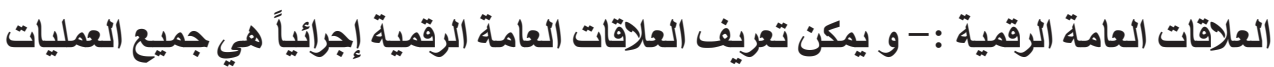

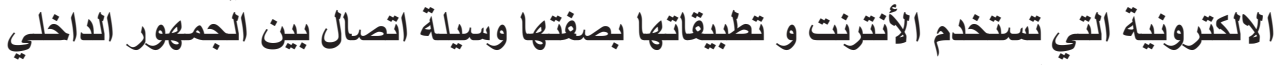

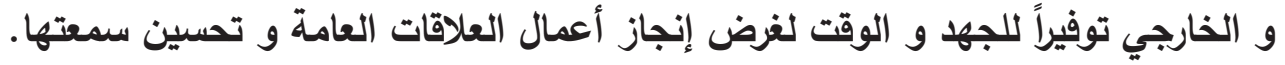

\section{المدخل النظري للبحث : المثات}

\section{أولاً : مفهوم العلاقات العامة الرقمية ووظائفها}

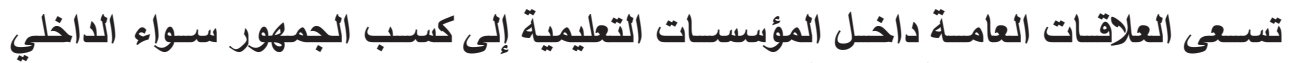

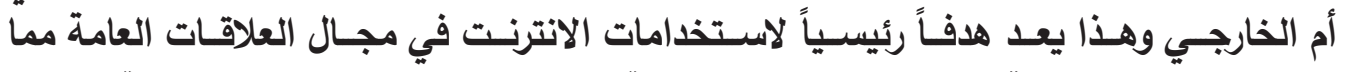

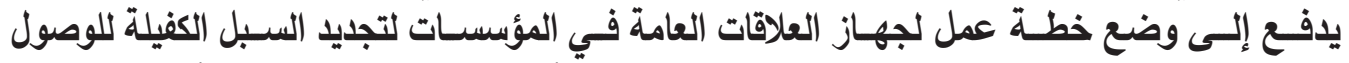

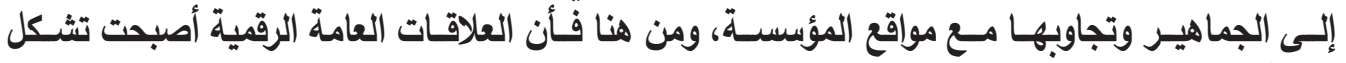

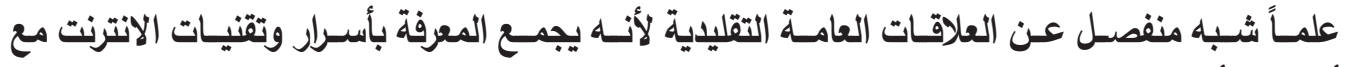
أصسول وأسـرار العلاقـات العامة المعروفـة ونتوقع تطوير عمل العلاقات العامـة في عصر الاتصال

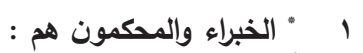

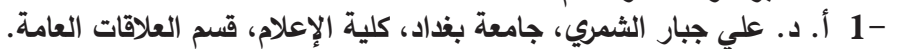
2-

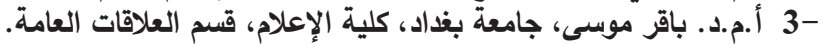

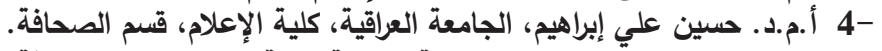

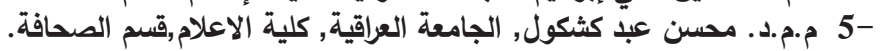


الالكترونـي المباشـر بالجمهـور أو أي مكان أخـر في مختــف دول العالم(v).

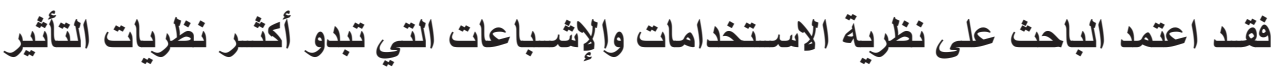

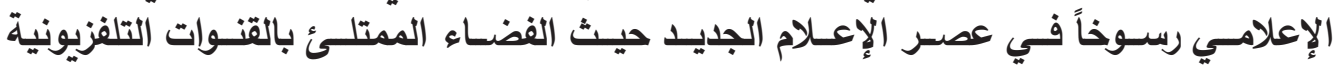

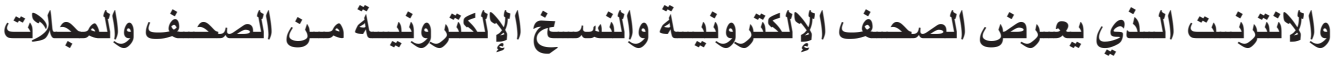

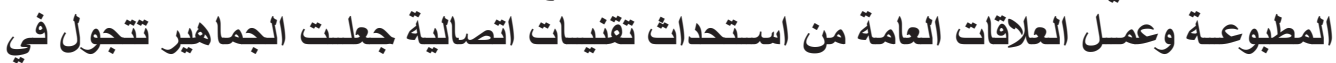

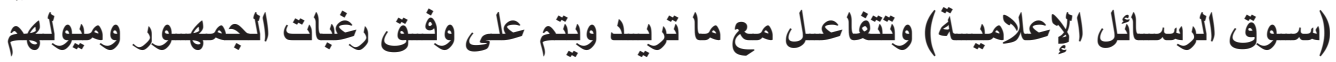

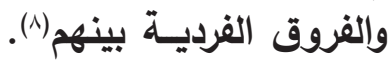

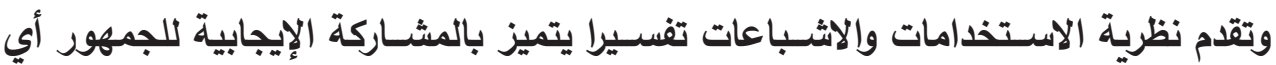

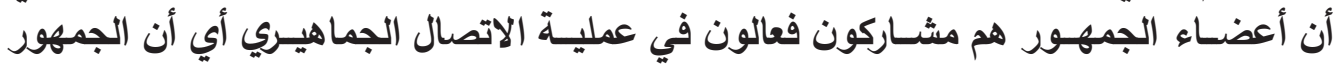

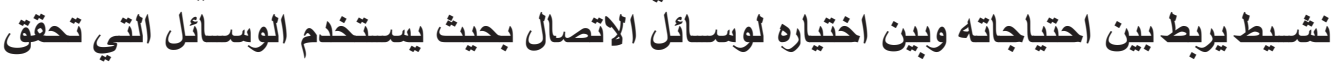

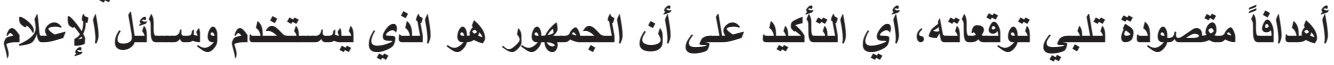

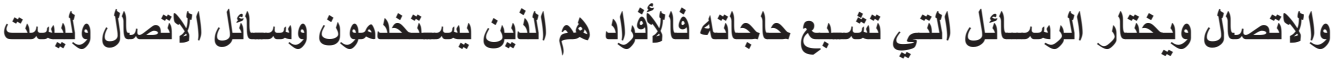

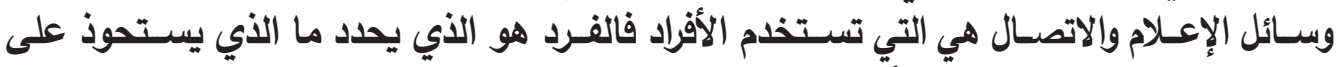

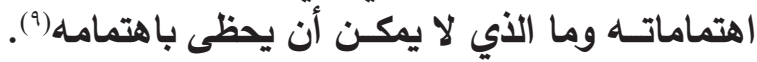

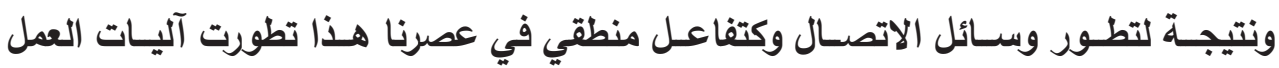

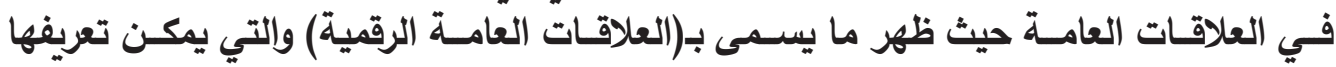

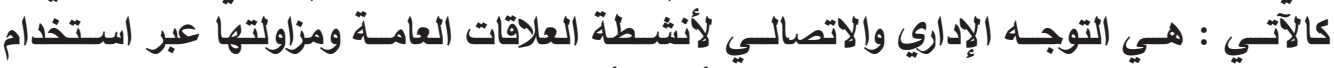

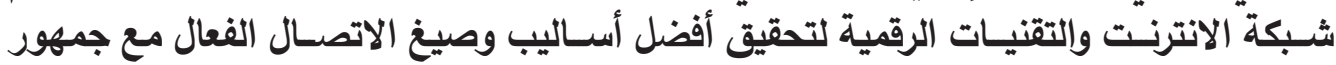

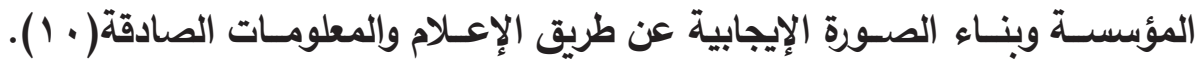

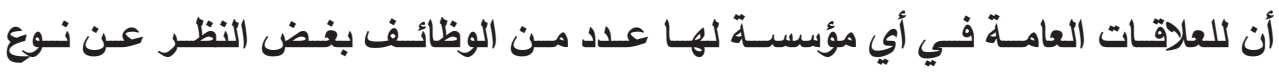

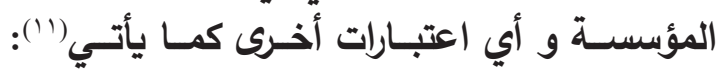
ا ـ إجراء الأبحاث والدراسات لتوفير قاعدة معلومات مناسبة. r. تنظيـم أعمـال المؤسسـة عـن طريـق المتابعة ومد جسـور تواصـل بينها وبيـن جماهيرها الاخليـة والخارجيـة وأدارتها. r. تقديم النصح والمشورة لمن يحتاجها أو عند الضرورة. إذاً وظيفة العلاقات العامة الرقمية تتسم بطبائع أساسية هي : ا ـ طبيعـة اتصاليـة إعلامية. r ـ طبيعة اجتماعية نفسية. r. r. طبيعة علمية بحتة. ع. طبيعة إدارية توجيهية.

\begin{tabular}{l|c} 
& العلة الباحث الإعلامي \\
\hline$V$ & (rv (rv ( )
\end{tabular}


وهناك مَنْ بين أن وظائف العلاقات العامة الرقمية هي كالآتي(r'):

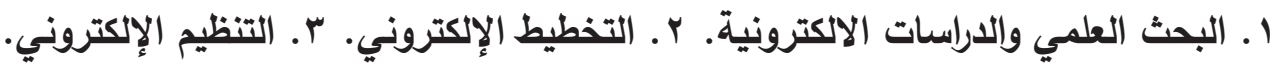
ء ـ الإنتاج الإكتروني للمواد الإعلامية. هـ الاتصال الإكتروني. 7. وعلـى اعتبـار أن العلاقـات العامة الرقمية كوسـيلة اتصال هناك جملة مسن الوظائف التي تؤديها وهي(") ا. الاتصال الداخلي بالمؤسسة مع ربطه بشبكة الأنترنت للاتصال بالجمهور الداخلي في

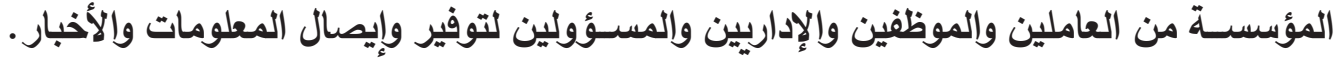

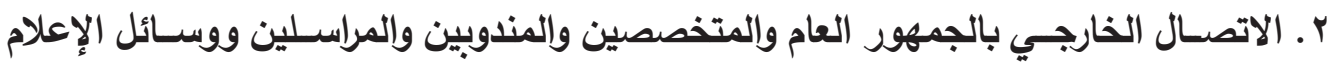

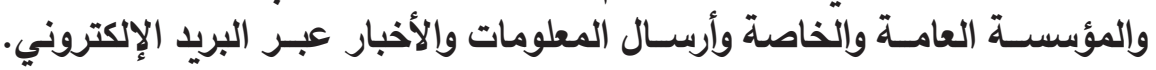

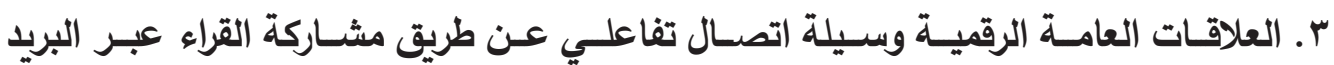

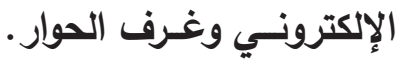

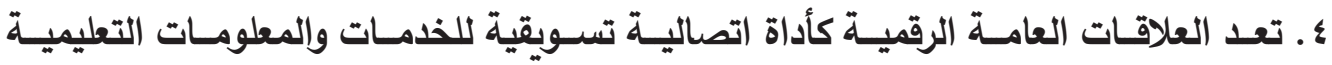

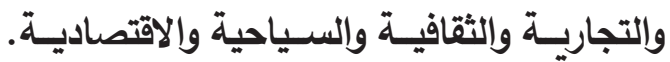

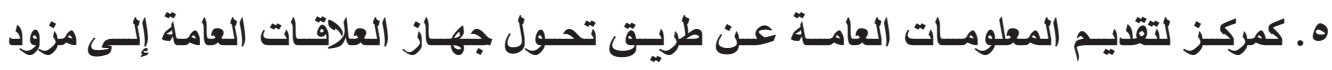
للخدمـات العلمية. ثانياً: استخدامات العطية، العلاقات العامة الرقمية للعلاقات العامة الرقمية استخدامات رئيسة في المؤسسات التعليمية وهي كالآتي(؛ (1): ا ـ تصميـم موقـع المنظمـة الإلكترونـي بحيـث يمثـل أداة جوهريـة وحيويـة للاتصــال

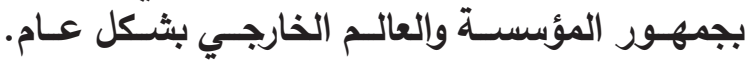

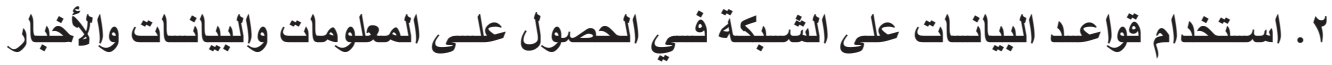

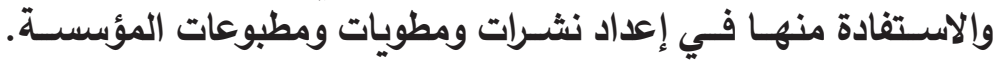

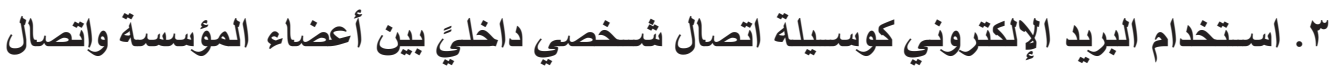

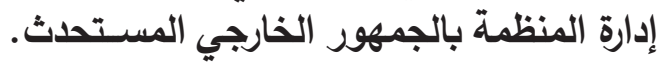

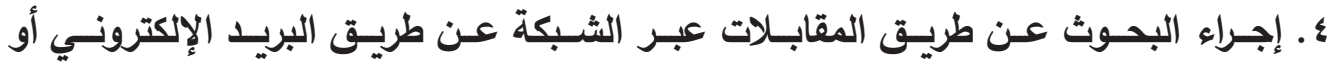

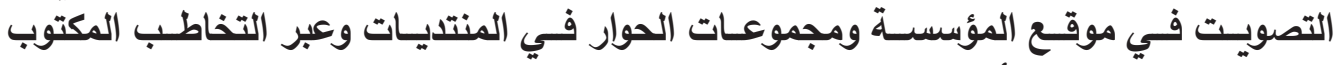

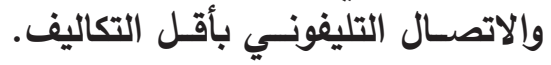
هـ التعـرف علـى صــورة المؤسســة عن طريق ما ينشـر من قبل وســائل الإعلام والمنافسـين والمستخدمين. 
7 . تصفــح المواقع المؤسسـة ومراكز الأبحـاث والمعاهد والجامعات والتعرف على أنشـطة هذه المؤسسات.

V. الإفادة من نقل الملفات في الشبكة للحصول على المعلومات والبيانات والصور . وعلى ضوء ذلك فأن أهمية العلاقات العامة الرقمية في المؤسسات التعليمية يمكن أجمالها بالآتي (10):

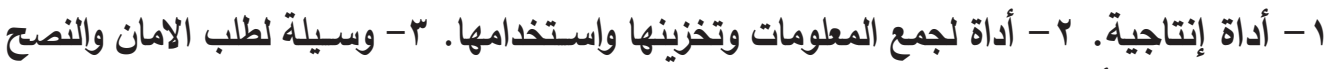

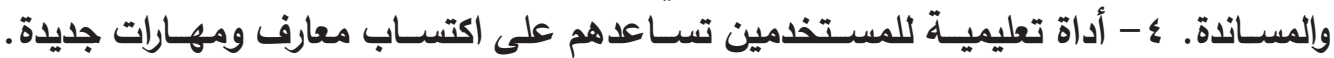

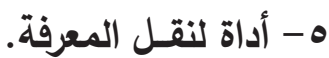

ثالثاً : جمهور العلاقات العامة الرقة الرقية

أن ممارسـي العلاقات العامة الرقمية هم بمنزبة حلقة وصل بين المؤسسـات التي يمثلونها

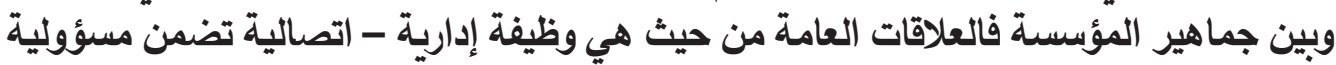

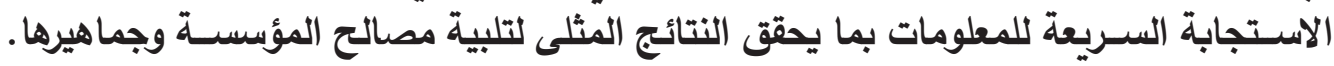
وإنطلاقاً من ذلك فأن جماهير العلاقات العامة في الجامعات هي(')": أ. الطـلاب. ب. الإدارة. ج. أعضـاء هيئـة التدريسـ. د. المجتــع المحلـي ـ هـ. أوليـاء أمور الطلبـة والخريجون. و. رجال الإعلام. ز. الجماعات المهنية. ح. الهيئات الحكومية.

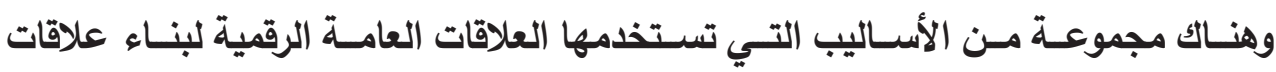

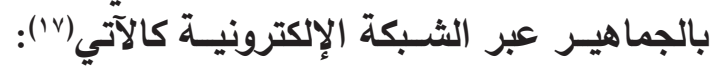

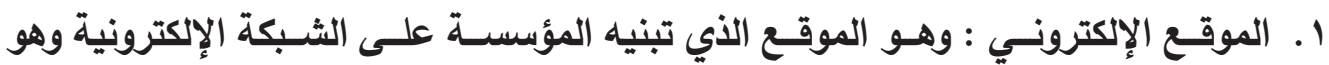

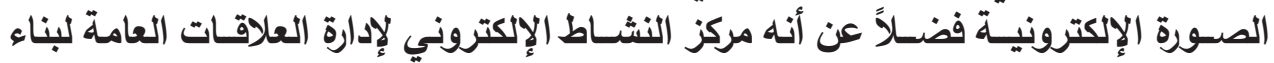
علاقاتها مع الجماهيـر الإلكترونية.

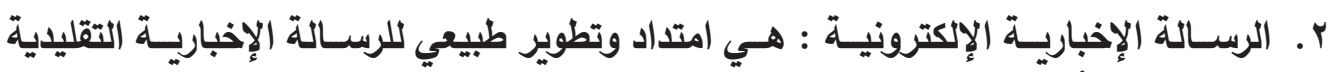

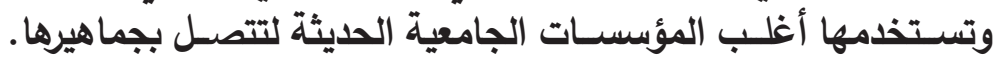

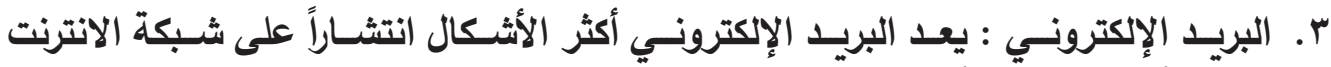

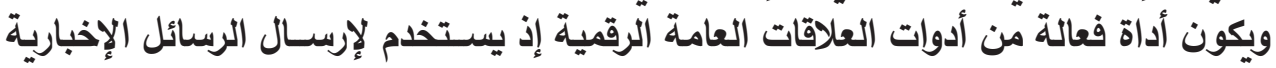

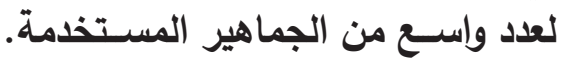

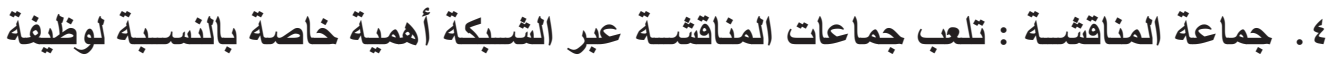

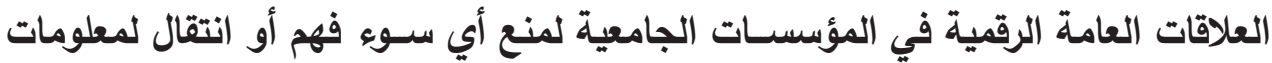
غيـر صحيحة عنها. ه. مواقـع التواصـل الاجتماعـي : تـؤدي مواقـع التواصـل الاجتماعـي وبالأخـص

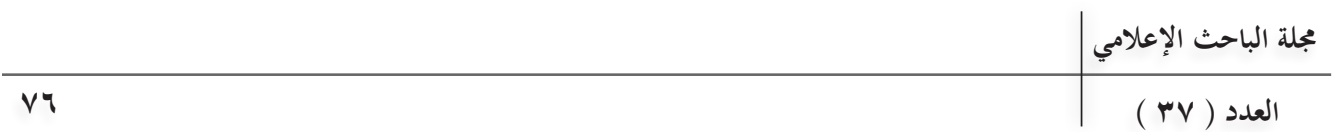




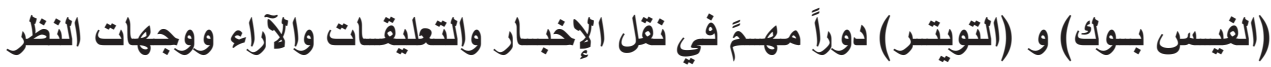

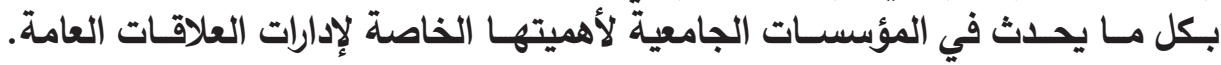

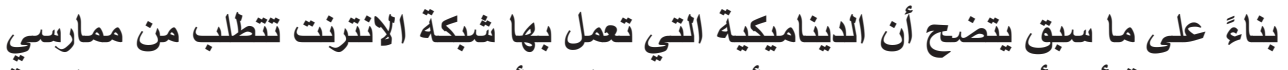

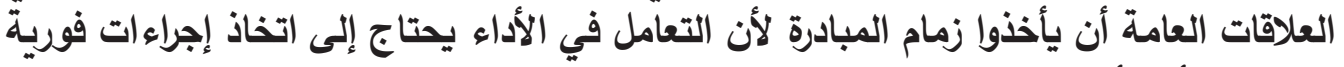

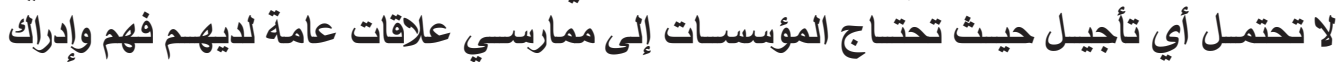

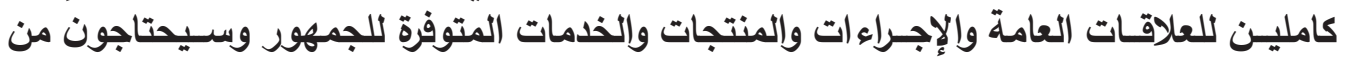

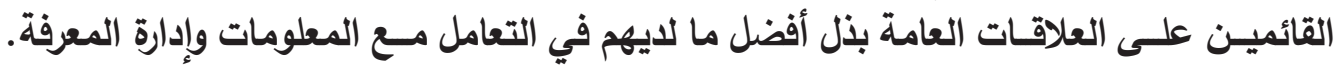

\section{الدراسة المسحية}

\section{عرض وتفسير نتائج الدراسة المسحية}

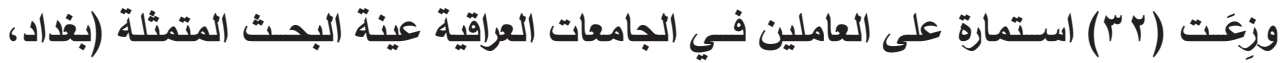

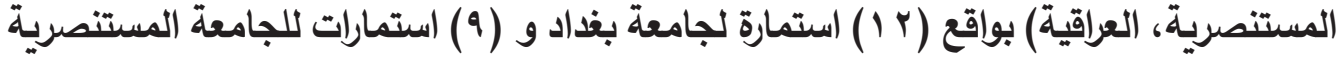

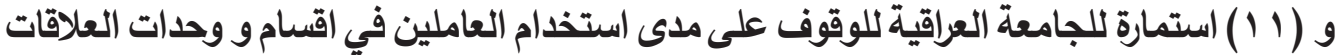

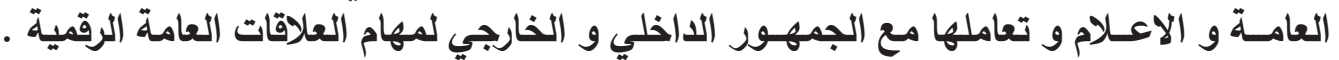

\section{أولاً : خصائص المبحوثين}

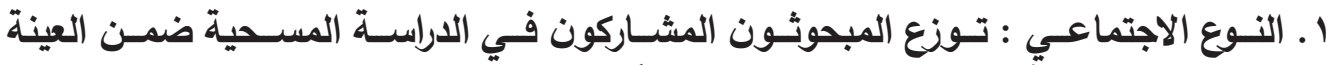

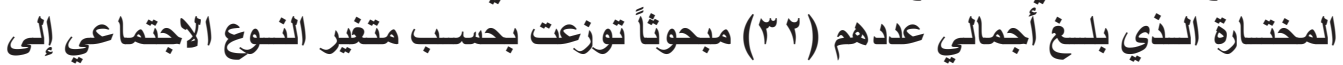

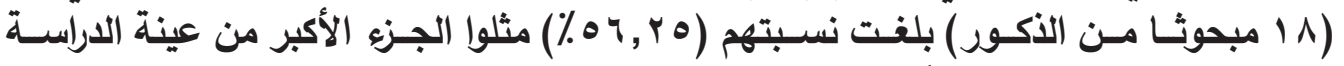

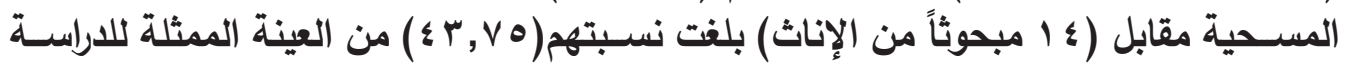

$$
\text { وكمـا موضح في الجدول (1) مبله }
$$

جدول ( 1) يبين التوزيع النسبي لعدد المبحوثين بحسب النوع الاجتماعي للجامعات العراقية

\begin{tabular}{|c|c|c|c|}
\hline النسبة المئوية & التكرار & النوع الاجتماعي & $ت$ \\
\hline$\% 07, Y 0$ & 11 & الأكور & 1 \\
\hline$\% \varepsilon r, v_{0}$ & $1 \leqslant$ & الإناث & r \\
\hline$\% 1 \ldots$ & ru & & المجموع \\
\hline
\end{tabular}

ب. المسـتويات العمريـة : توزعت المعدلات العمرية للعامليـن في عمل العلاقات العامة الرقمية في الجامعات العراقية (المشـاركين في البحث) بين مسـتونيات عدة تم تقسيمهم كما يلي : 


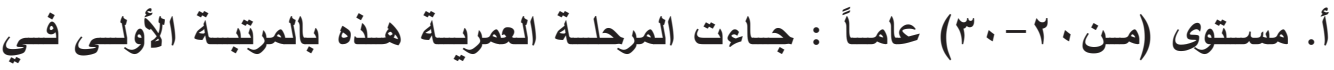

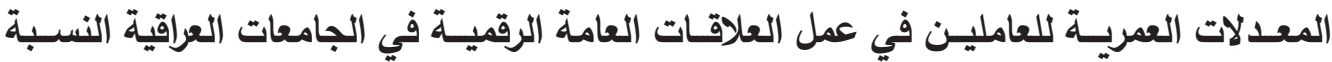

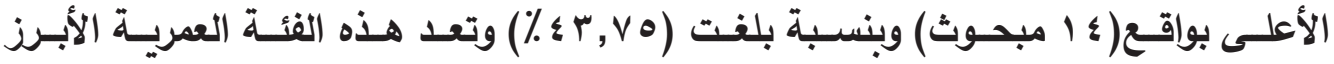

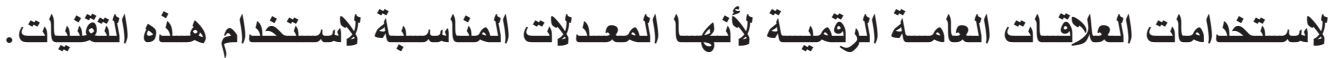

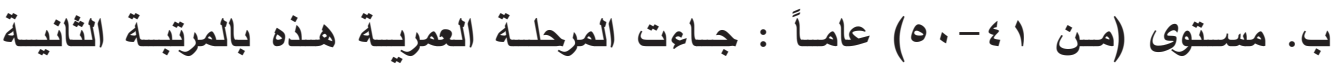

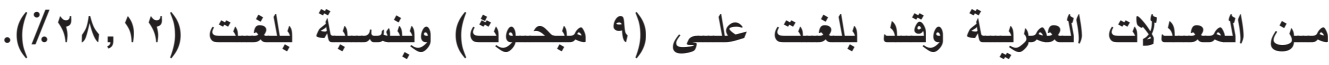

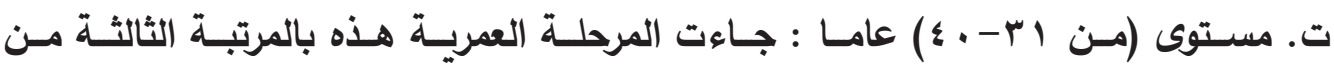

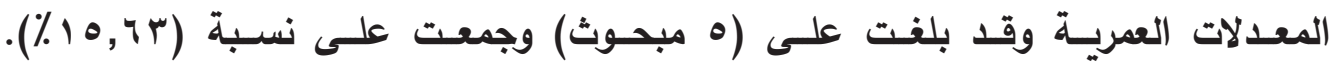

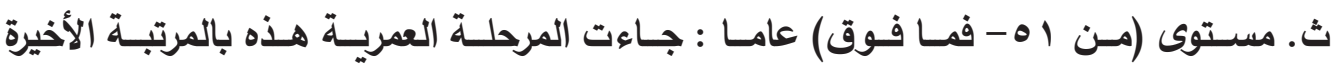

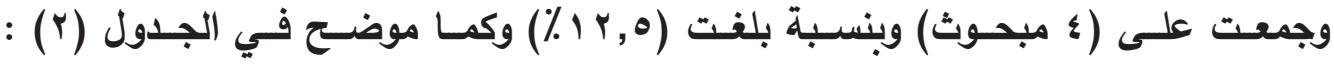
جـول (Y) يبين التوزيع النسـبي للمعدلات العمريـة للمبحوثين في الجامعات العراقية

\begin{tabular}{|c|c|c|c|c|}
\hline المرتبة & النسبة المئوية & التكرار & المعدلات العمرية & ت \\
\hline الأولى & $\% \leqslant r, v \theta$ & $1 \leq$ & 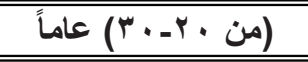 & 1 \\
\hline الثانتية & $\% Y \wedge, 1 Y$ & $\bar{q}$ & (من إيـ ، 0) عاماً & $r$ \\
\hline الثالثة & \% & 0 & 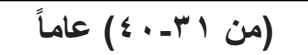 & $r$ \\
\hline الرابعة & $\% 1 r, 0$ & $\varepsilon$ & (من اه فما فوق) عاماً & $\varepsilon$ \\
\hline & $\% 1 \ldots$ & $r Y$ & & لمجموع \\
\hline
\end{tabular}

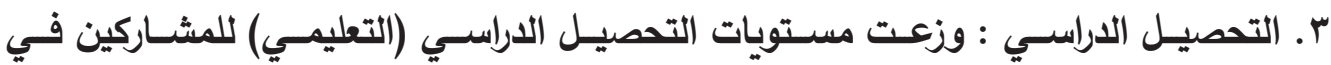

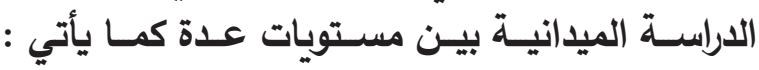

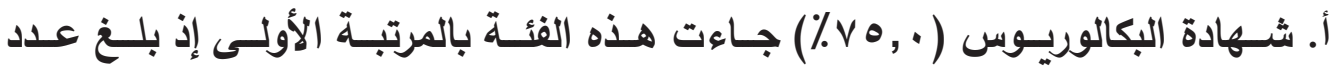

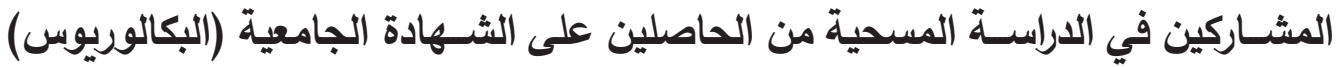

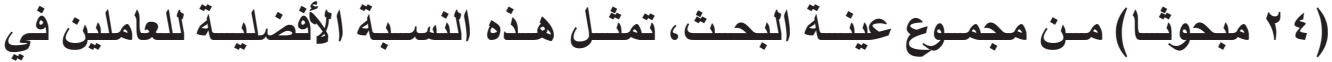

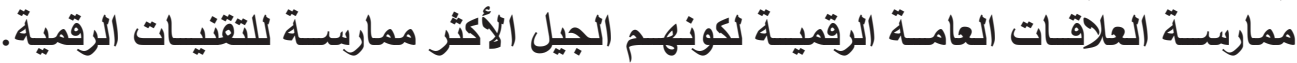

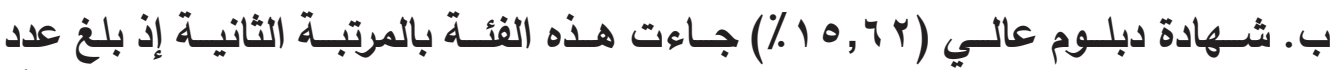
المشـاركين في الدراسـة المســية من الحاصلين على شهادة الدبلوم العالي (ه مبحوثاً) من عينـة البحث.

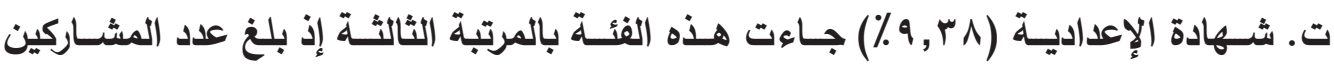


في الدراسـة المســية من الحاصلين على الثــهادة (الإعدادية) (ثلاثة مبحوثيـن) من عينة البحـث و كمـا موضـح في الجـدول (r).

جدول (ץ) يبين التوزيع النسبي للتحصيل الدراسي (التعليمي) للمبحوثين في الجامعات العراقية

\begin{tabular}{|c|c|c|c|c|}
\hline المرتبة & النسبة المئوية & التكرار & التحصيل الدراسي & ث \\
\hline الأولى & $\% v_{0},$. & Y & البكالوريوس & 1 \\
\hline الثانية & $\% 10,1 Y$ & 0 & دبلوم عالي (خريج معهد) & $r$ \\
\hline الثالثة & $\% q, r \wedge$ & 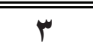 & الإعدادية & $\bar{~}$ \\
\hline & $\% 1 \ldots$ & rr & & المجموع \\
\hline
\end{tabular}

ـ ـ مكان العمل : جاءت جامعة بغداد بالمرتبة الاولى بعد ان جمعت على تكرار (Y I I ) ونسـبة

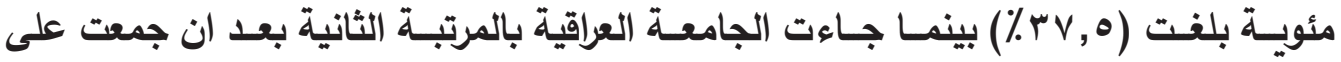

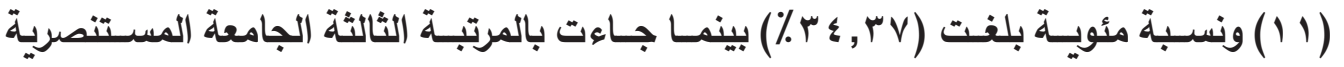

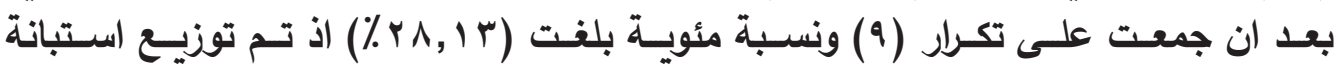

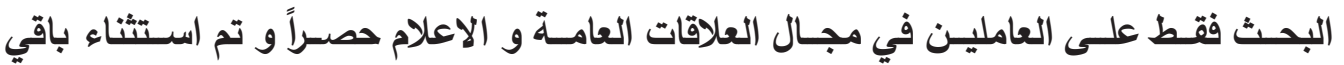

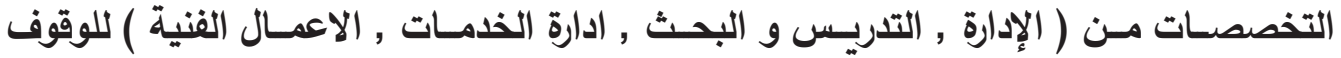

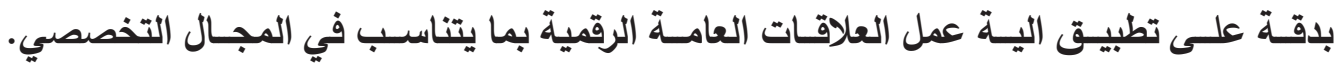
جدول (ع) يبين التوزيع النسـبي لمكان العاملين في العلاقـات العامة الرقمية عينة البحث

\begin{tabular}{|c|c|c|c|c|}
\hline المرتبة & النسبة المئوية & التكرار & مجال العمل & ت \\
\hline الأولى & $\% \Gamma v, 0$ & ir & جامعة بغداد & 1 \\
\hline الثانية & $\% r \varepsilon, r v$ & 11 & الجامعة العراقية & $\bar{r}$ \\
\hline \multirow[t]{2}{*}{ الثالثة } & $\% \curlyvee \wedge, 1 r$ & $\overline{9}$ & الجامعة المستنصرية & $\bar{\mu}$ \\
\hline & $\% 1 \ldots$ & rr & \multicolumn{2}{|c|}{ المجموع } \\
\hline
\end{tabular}

هـ ســنوات العــل والخبـرة في الجامعات العراقية : تمثلت ســوات العمـل والخبرة في الجامعات

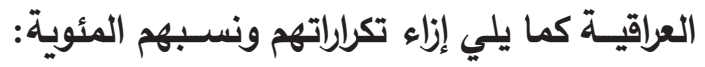
أ. (من V-

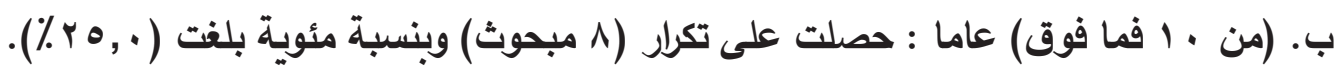

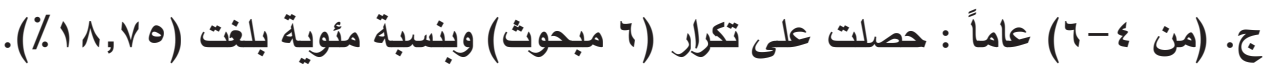




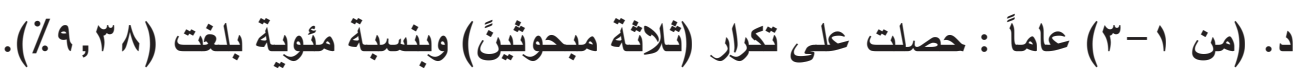
وكما موضح تسلسل تراتيبيتها في الجدول (0) ضمن عينة البحث. جدول (•) يبين التوزيع النسـبي لسـنوات العمل والخبرة في الجامعات العراقية فئه

\begin{tabular}{|c|c|c|c|c|}
\hline المرتبة & النسبة المئوية & التكرار & سنوات العمل والخبرة & ت \\
\hline الأولى & $\% ๕ \neg, \wedge \vee$ & 10 & 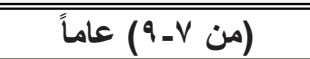 & 1 \\
\hline الثانية & $\%$ Y, & $\Lambda$ & من ( • ا فما فوق) عاماً & r \\
\hline الثالثة & $\% \wedge \wedge, \vee 0$ & 7 & (من ع - آ) عاماً & $\bar{\mu}$ \\
\hline الرابعة & $\% q, \Gamma \wedge$ & $r$ & (من 1-"r) عاماً & $\varepsilon$ \\
\hline & $\% 1 \ldots$ & 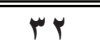 & & المجموع \\
\hline
\end{tabular}

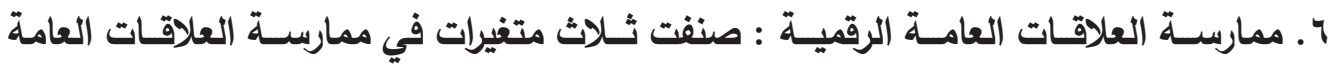

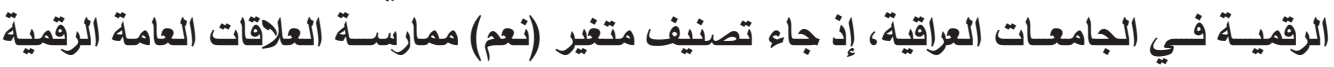

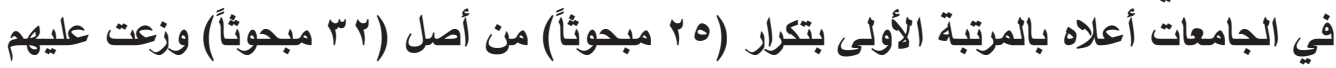

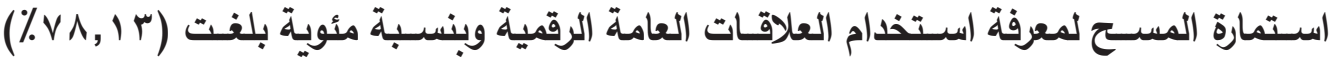

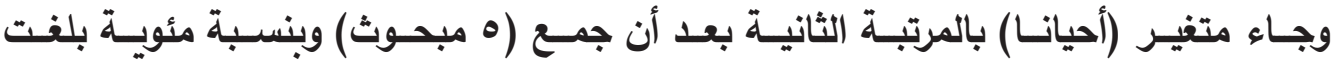

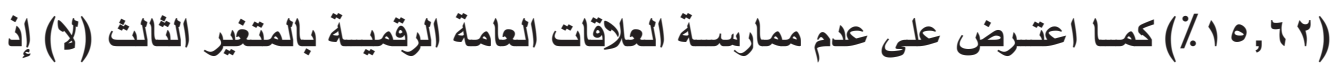

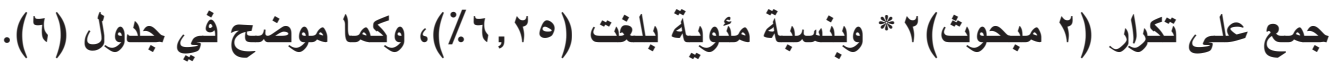
جدول (†) يبين التوزيع النسبي لممارسـة العلاقات العامة الرقمية في الجامعات العراقية

\begin{tabular}{|c|c|c|c|c|}
\hline المرتبة & النسبة المئوية & التكرار & الممارسة & $ت$ \\
\hline الأولى & $\% \vee \wedge, 1 \mu$ & ro & ن نعم & 1 \\
\hline الثانية & $\% 10,7 r$ & 0 & أحيانا & $r$ \\
\hline الثالثة & $\%$ \% Y० & $r$ & $y$ & $r$ \\
\hline & $\% 1 \ldots$ & rr & & المجموع \\
\hline
\end{tabular}

ثانيـاً : إجابـة المبحوثيـن على اســمارة المســح الخاصــة للعاملين في مجال العلاقـات العامـة

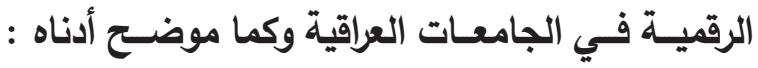

جدول (V) يبين التوزيع النسبـي لاسـتخدام العلاقات العامة الرقمية في الجامعات العراقية 


\begin{tabular}{|c|c|c|c|c|c|c|c|c|c|c|c|c|c|}
\hline \multicolumn{2}{|c|}{ المجموع } & \multicolumn{2}{|c|}{ لا أتفق بشدة } & \multicolumn{2}{|c|}{ لا أتفق } & \multicolumn{2}{|c|}{ محايد } & \multicolumn{2}{|l|}{ اتفق } & \multicolumn{2}{|c|}{ |تفق بشدة } & \multirow{2}{*}{ نوع الفقرة } & \multirow{2}{*}{$ت$} \\
\hline$\%$ & ك5 & $\%$ & ك5 & $\%$ & |5 & $\%$ & ك5 & $\%$ & |5 & $\%$ & |5 & & \\
\hline $1 \cdots$ & rr & صفز & صفر & $7, r \circ$ & $r$ & $r \wedge, \mid r$ & 9 & $\varepsilon \neg, \wedge \wedge$ & 10 & $1 \wedge, \vee 0$ & 7 & 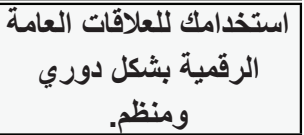 & 1 \\
\hline $1 \cdots$ & rr & $7, Y 0$ & $r$ & $\mid r, 0$ & $\varepsilon$ & ro, & $\Lambda$ & $\varepsilon \cdot, 7 \mu$ & $1 T$ & $10,7 r$ & 0 & "يمثُل استخداملك للعلاقات العامة الرقمية جزع من & $r$ \\
\hline $1 \ldots$ & rr & $q, Y 0$ & $r$ & $1 \wedge, \vee 0$ & 7 & $r r, \cdot$ & V & $r v, 0$ & $1 Y$ & $1 r, 0$ & $\varepsilon$ & الرقاتخدام العلاقات العامة تعميق تواصل & $r$ \\
\hline $1 \cdots$ & $r r$ & $r, r_{0}$ & 1 & $q, r_{0}$ & $r$ & $\varepsilon \varepsilon$, & $1 \varepsilon$ & $r \varepsilon, r o$ & 11 & $q$, ro & $r$ & 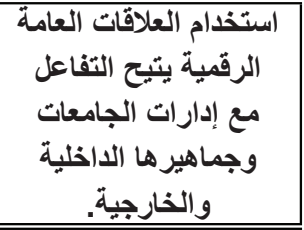 & $\varepsilon$ \\
\hline $1 \ldots$ & صفز & صفر & صفز & $Y, Y \odot$ & $r$ & $r v, 0$ & $1 \%$ & •., . & 17 & $7, Y \circ$ & $r$ & 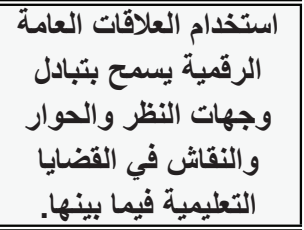 & $\bullet$ \\
\hline $1 \ldots$ & $r r$ & $r, r o$ & 1 & $q, Y \bullet$ & $\boldsymbol{r}$ & $10, v 0$ & • & or, & $1 \mathrm{~V}$ & $1 \wedge, \vee 0$ & 7 & الأرشيف الإلكتروني الخئي & 7 \\
\hline $1 \ldots$ & rr & $\bullet, r \theta$ & $r$ & $1 \wedge, v 0$ & 7 & ro,. & $\Lambda$ & $\varepsilon r, v \bullet$ & $1 \leq$ & $7, r o$ & $r$ & 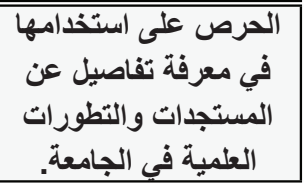 & V \\
\hline $1 \cdots$ & rr & $1 \Lambda, Y 0$ & 7 & $Y, Y \bullet$ & $Y$ & $r r, \cdot$ & $V$ & $\mu v, 0$ & $1 Y$ & $10, v 0$ & 0 & 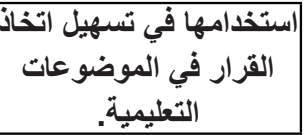 & $\Lambda$ \\
\hline $1 \ldots$ & $r r$ & صفر & صفر & $Y, Y \bullet$ & $r$ & $r \wedge$, & 9 & $07, Y \bullet$ & 11 & 9,0 & $r$ & تستخدم في التحضير & 9 \\
\hline
\end{tabular}

المحور الأول : استخدام العلاقات العامة الرقمية في الجامعات العراقية 1. كانت نسبة إجابة المبحوثين إزاء الفقرة (استخدامك للعلاقات العامة الرقمية بثكل دوري ومنظم)وفق تراتيبها تنازليا كالآتي : 46.88 أتفق، 6.25\% لا أتفق، وهذا يعني أن إجابات المبحوثين اتجهت نحو الاتفاق ضمن الفقرة أعلاه. 


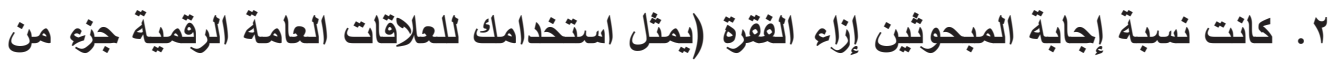

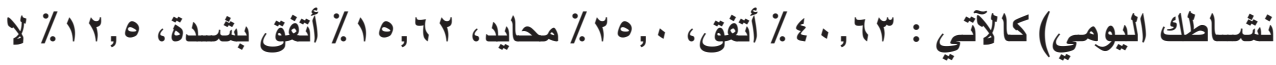

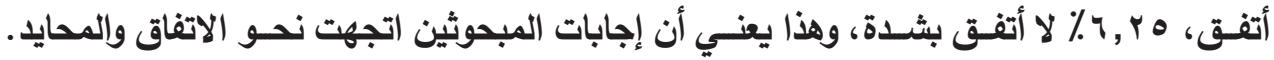
r. كانت نسبة إجابات المبحوثين إزاء الفقرة (استخدام العلاقات العامة الرقمية في تعميق تواصل

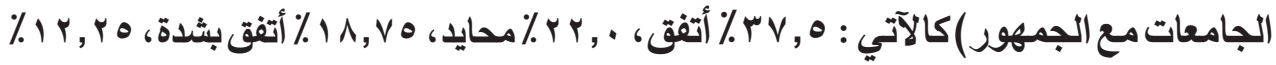

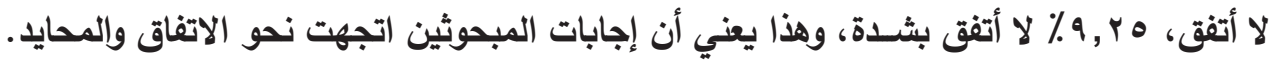
؛. كانت نسـبة إجابات المبحوثين إزاء الفقرة (اسـتخدام العلاقات العامة الرقمية يتيح التفاعل

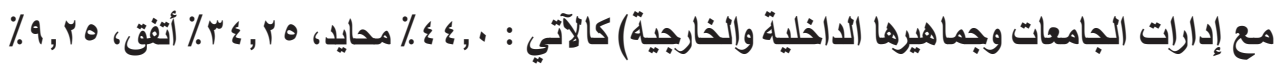

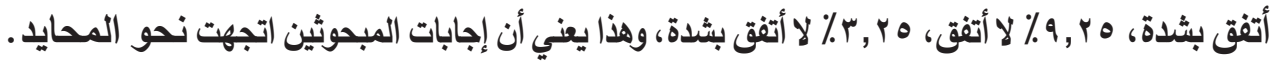
ه. كانت نسـبة إجابات المبحوثين إزاء الفقرة (اســخدام العلاقات العامة الرقمية يســـح بتبادل

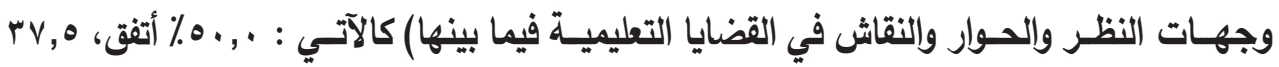

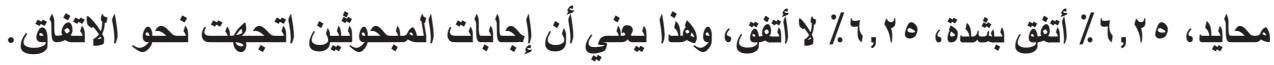
צ. كانـت نسـة إجابـات المبحوثين إزاء الفقرة (اســخدامها فـي تنظيم الأرشـيف الإكتروني

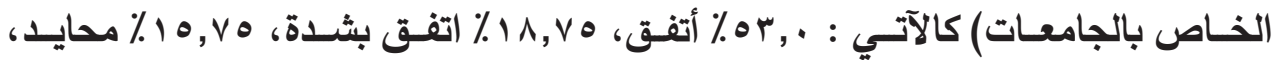

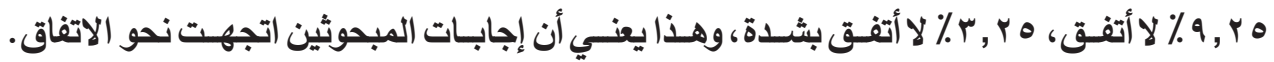
V. كانـت نسـبة إجابـات المبحوثين إزاء الفقرة (الحرص على اســخدامها فـي معرفة تفاصيل

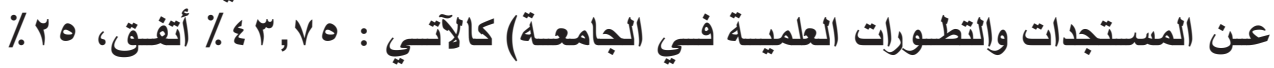

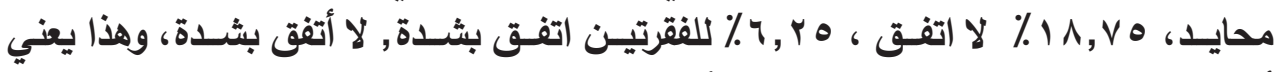
أن إجابـات المبحوثيـن اتجهت نـــو الأتفاق.

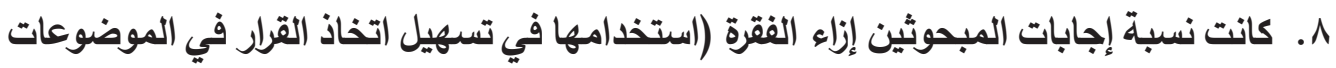

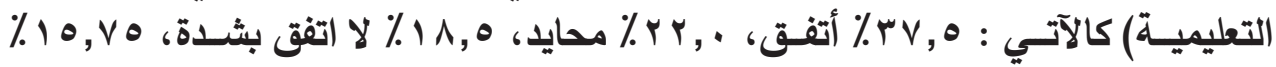

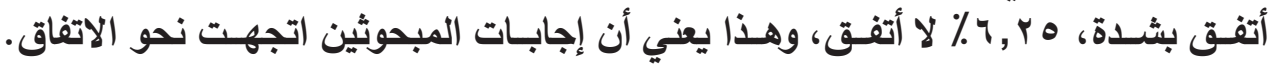
9. كانـت نسـبة إجابات المبحوثيـن إزاء الفقرة (تسـتخدم في التحضير والترتيـب للاجتماعات

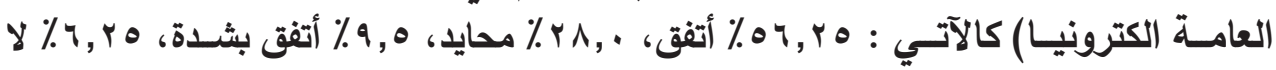

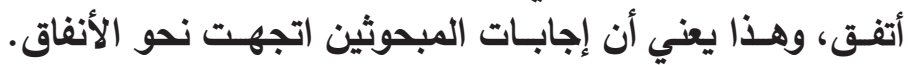

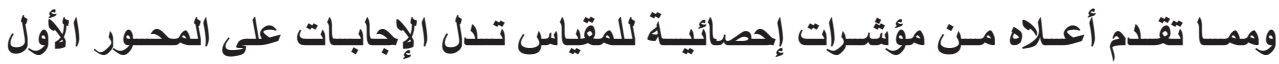

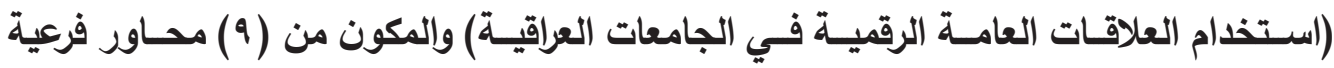

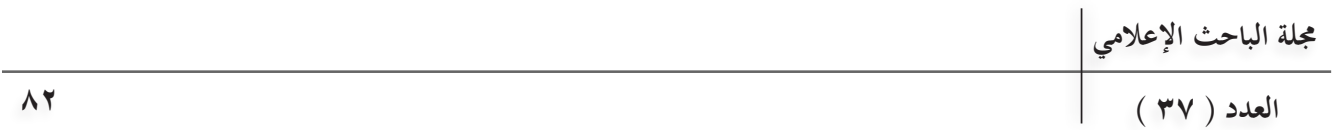


كانـت إجابـات المبحوثيـن (الاتفــاق) و (الحياديـة) متقدمــة عـن الإجابـات الأخـرى وهذا يدل

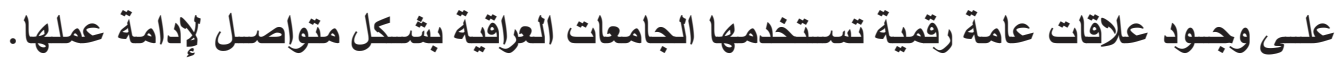
جـول (^) يبين تطبيق العلاقات العامـة الرقمية في الجامعات العراقية

\begin{tabular}{|c|c|c|c|c|c|c|c|c|c|c|c|c|c|}
\hline \multicolumn{2}{|c|}{ المجموع } & \multicolumn{2}{|c|}{ لا بشدة أتفق } & \multicolumn{2}{|c|}{ لا أتفق } & \multicolumn{2}{|c|}{ محايد } & \multicolumn{2}{|c|}{ اتفق } & \multicolumn{2}{|c|}{ بشدة } & \multirow{2}{*}{ نوع الفقرة } & \multirow[t]{2}{*}{$ت$} \\
\hline$\%$ & ك5 & $\%$ & ك5 & $\%$ & ك5 & $\%$ & S & $\%$ & ك5 & $\%$ & S & & \\
\hline : & $i$ & 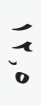 & m & $\begin{array}{l}5 \\
z \\
\vdots \\
0\end{array}$ & + & $\underset{1}{z}$ & a & 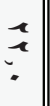 & $<$ & : & 7 & فتيح العلاقاتات العامة الرقمية مشاركة الآخرين & 1 \\
\hline : & 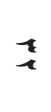 & $\frac{5}{1}$ & e & $\begin{array}{l}j \\
z \\
\vdots \\
0\end{array}$ & + & $\begin{array}{l}m \\
\hat{1} \\
\dot{c}\end{array}$ & $m$ & \begin{tabular}{l||l||}
$z$ & \\
$z$ & \\
0 &
\end{tabular} & + & $\underline{a}$ & $m$ & القوانين واللاقواتيح التامة الرقة بالجامعاتة بعرض. & $r$ \\
\hline : & 1 & $\begin{array}{l}1 \\
0 \\
0\end{array}$ & - & $\begin{array}{l}0 \\
\vdots \\
0\end{array}$ & 1 & $\dot{m}^{m}$ & $\bar{z}$ & 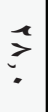 & مـ & $\begin{array}{l}5 \\
\vdots \\
\vdots \\
0\end{array}$ & + & تعمل على توفير محركات بحث & $r$ \\
\hline : & 1 & $\frac{5}{1}$ & 1 & $\ddot{a}$ & on & $\frac{1}{a}$ & $=$ & $\stackrel{?}{\because}$ & $>$ & $\begin{array}{l}1 \\
5 \\
\vdots \\
0\end{array}$ & $<$ & 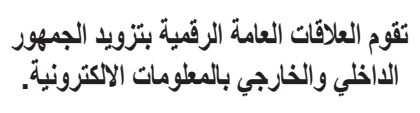 & $\varepsilon$ \\
\hline ! & 1 & ta & 1 & $\begin{array}{l}0 \\
0 \\
0\end{array}$ & 1 & 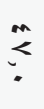 & $\overline{0}$ & $\begin{array}{l}1 \\
\vdots \\
\vdots \\
0\end{array}$ & $<$ & $\begin{array}{l}0 \\
\vdots \\
\vdots \\
0\end{array}$ & 0 & والعلاقات العامة الرقمية توفر البيات التيانات & 0 \\
\hline : & 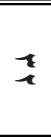 & $\begin{array}{l}1 \\
1 \\
0\end{array}$ & - & $\begin{array}{l}0 \\
1 \\
0\end{array}$ & 1 & $\sum_{0}^{1}$ & $\bar{z}$ & $\begin{array}{l}1 \\
2 \\
0 \\
0\end{array}$ & ? & $\begin{array}{l}3 \\
2 \\
\vdots \\
0\end{array}$ & - & 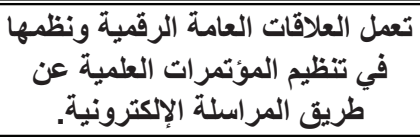 & 9 \\
\hline : & 1 & ' & ' & $\begin{array}{l}1 \\
a \\
1 \\
0\end{array}$ & $m$ & $\ddot{<}$ & $\overline{0}$ & 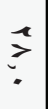 & م & $\dddot{1}$ & $m$ & تعزز التواصل بين الأقسام المختلفة & $v$ \\
\hline : & $\underline{1}$ & ' & ' & $\begin{array}{l}5 \\
\vdots \\
\vdots \\
0\end{array}$ & 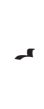 & $\vdots$ & 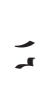 & $\because$ & $>$ & $\begin{array}{l}5 \\
0 \\
0\end{array}$ & 4 & أمكانية تبادل الآراء و التعليمات في & $\wedge$ \\
\hline : & $i$ & ' & ' & $\begin{array}{l}3 \\
\vdots\end{array}$ & $<$ & $\underbrace{1}_{0}$ & $\bar{a}$ & $\begin{array}{l}1 \\
5 \\
1 \\
0\end{array}$ & ? & $\begin{array}{l}0 \\
a \\
0\end{array}$ & 7 & و والمقترحيات فتيم إيصيم التعليمات الثكوى & 9 \\
\hline $\overrightarrow{0}$ & N & ' & ' & $\begin{array}{l}O \\
\text { N }\end{array}$ & $N$ & $\begin{array}{l}\vec{\omega} \\
\dot{v}\end{array}$ & $\vec{A}$ & $\begin{array}{l}\text { N } \\
\text { N }\end{array}$ & 0 & $\underset{\text { G }}{\stackrel{N}{J}}$ & $v$ & 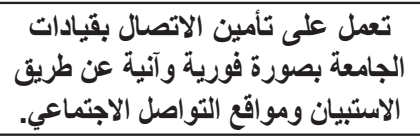 & 10 \\
\hline
\end{tabular}


المحـور الثاني : تطبيـق العلاقـات العامة الرقمية في الجامعات العراقية

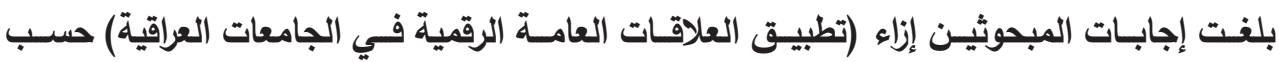

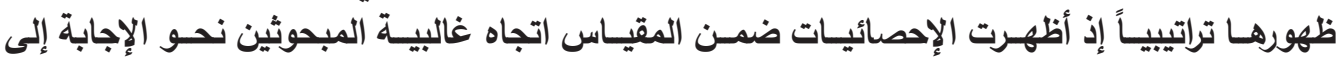

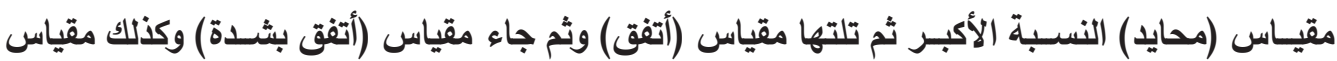

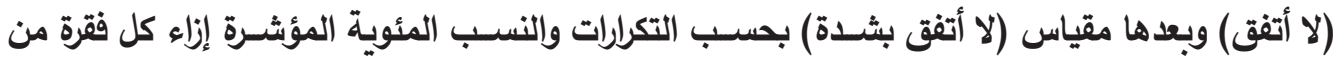

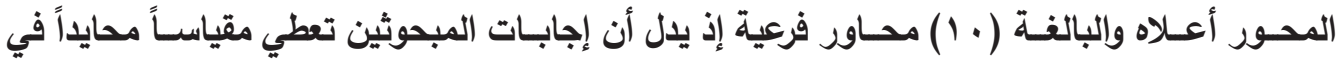
تطبيق العلاقات العامة الرقمية في الجامعات وهو مؤشر إيجابي وخاصة تلتها الإجابة بمقياس (أتفق). جـول (9) يبين تفضيل العلاقات العامـة الرقمية في الجامعات العراقية

\begin{tabular}{|c|c|c|c|c|c|c|c|c|c|c|c|c|c|}
\hline \multicolumn{2}{|c|}{ 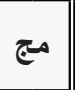 } & \multicolumn{2}{|c|}{ 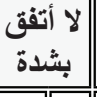 } & \multicolumn{2}{|c|}{ لا لا أتفق } & \multicolumn{2}{|c|}{ 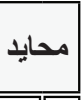 } & \multicolumn{2}{|c|}{ اتفق } & \multicolumn{2}{|c|}{ بثنقة } & \multirow{2}{*}{ 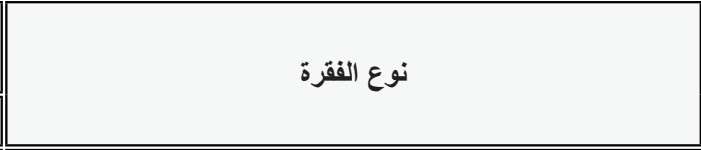 } & \multirow[t]{2}{*}{ [: } \\
\hline$\%$ & (5) & $\%$ & S & $\%$ & s] & $\%$ & || & $\%$ & 5 & $\%$ & 5] & & \\
\hline : & in & ' & ' & 1 & ' & \begin{tabular}{l|l|}
1 & \\
3 & \\
1 &
\end{tabular} & |هـ & 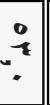 & 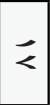 & \begin{tabular}{l|l||} 
& \\
2 & \\
0
\end{tabular} & 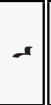 & |تسهم في تحقيق معايير جودة التعليم على وفق مقياس (Q.S) العالمي. & 一 \\
\hline : & 1 & ' & ' & ' & $\cdot$ & \begin{tabular}{l||}
1 \\
3 \\
1 \\
0
\end{tabular} & |هـ || & $\because$ & $=$ & 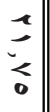 & $<$ & تنتج التفاعل والمشاركة في بناء علاقات جديدة مع زوار الموقع. & 4 \\
\hline ? & \begin{tabular}{l|l}
1 \\
1
\end{tabular} & ' & ' & 1 & ' & $\because$ & $>\|$ & \begin{tabular}{l|l||}
3 & 0 \\
$\vdots$ \\
0 \\
0
\end{tabular} & $\overrightarrow{0}$ & \begin{tabular}{l||}
1 \\
2 \\
1 \\
0
\end{tabular} & ـ | & فتح أفاق التواصل مع الجامعة والجامعات الأخرى. & 1 \\
\hline- & \begin{tabular}{l|l|}
1 \\
1
\end{tabular} & ' & ' & 1 & $\cdot$ & 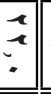 & $<$ & \begin{tabular}{ll|} 
\\
$\vdots$ \\
\end{tabular} & $<$ & $\because$ & $>$ & مشاركة العاملون في العلاقات العامة الرقمية في المجموعات & m \\
\hline 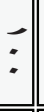 & in & ' & ' & 1 & ' & 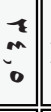 & $=$ & \begin{tabular}{l||r}
3 \\
$<$ \\
$<$ \\
\end{tabular} & $=$ & 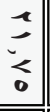 & $<$ & |تســهم في تســويق الجامعة وتعزيز سمعتها على المســتوى المحلي & - \\
\hline-1 & | & ' & ' & ' & ' & $\mid$ & - & $\because$ & $\mp$ & \begin{tabular}{l|l|}
1 \\
$\vdots$ \\
\end{tabular} & $m$ & تساعد العلاقات العامة الرقمية في مواجهة الأزمات التي تواجه الجامعات. & a \\
\hline : & 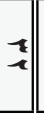 & ' & ' & 1 & $\cdot$ & 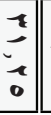 & . & $\stackrel{\circ}{-1}$ & $\overline{<}$ & 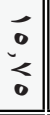 & $\circ$ & تساعد بخدماتها المتعددة على أقامة علاقات جيدة ومتفاعلة مع الإعلام. & $<$ \\
\hline 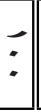 & 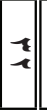 & ' & ' & 1 & ' & \begin{tabular}{l|l||}
1 & \\
3 & \\
1 & \\
0 &
\end{tabular} & + & \begin{tabular}{l||r|}
2 \\
$\vdots$ \\
0
\end{tabular} & $\overrightarrow{0}$ & $\because$ & $>$ & 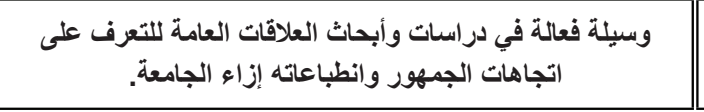 & $>$ \\
\hline • & 1 & ' & ' & $\cdot$ & ' & 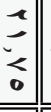 & $<$ & $\begin{array}{l}: \\
\\
\end{array}$ & 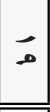 & 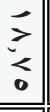 & 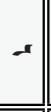 & تعد مصدر من مصادر توفير المعلومات الخاصة بالجامعة. & s \\
\hline . & $\mid$ & ' & ' & 1 & ' & & $\bar{z}$ & 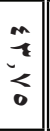 & $m$ & \begin{tabular}{l||l} 
& 0 \\
$\vdots$ & 0
\end{tabular} & . & 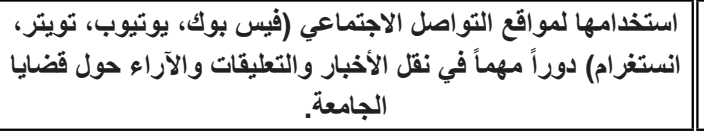 & $?$ \\
\hline
\end{tabular}


المحـور الثالث : تفضيل العلاقات العامة الرقمية في الجامعات العراقية

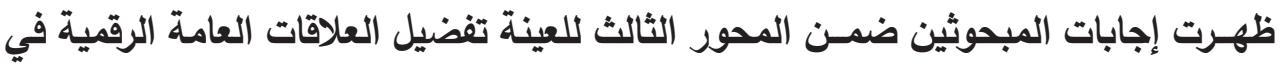

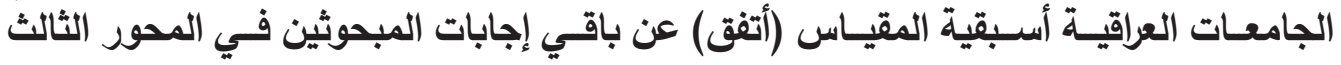

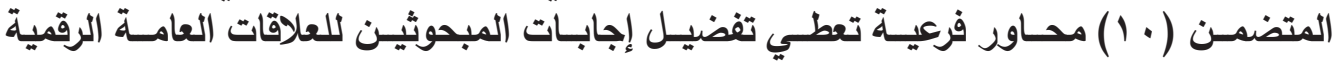

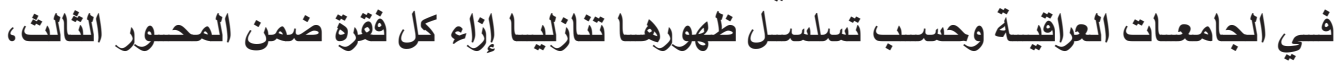

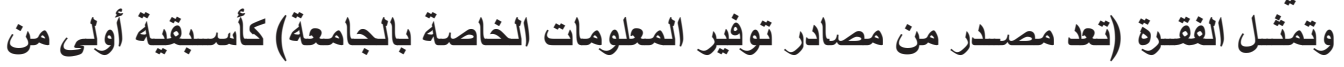
تفضيـلات المبحوثين كـون العلاقات العامة الرقمية توفر مصادر المعلومات الخاصة بالجالجامعة.

جـول ( • 1) يبين الهـف من اسـتخدام العلاقات العامـة الرقمية في الجامعات العراقية

\begin{tabular}{|c|c|c|c|c|c|c|c|c|c|c|c|c|c|}
\hline \multicolumn{2}{|c|}{ 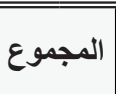 } & \multicolumn{2}{|c|}{ لا لأتفق } & \multicolumn{2}{|c|}{ لا أتفق } & \multicolumn{2}{|c|}{ 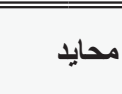 } & \multicolumn{2}{|c|}{ | اتفق } & \multicolumn{2}{|c|}{ اتفق بشدة } & \multirow[t]{2}{*}{ نوع الفقرة } & \multirow[t]{2}{*}{$ت$} \\
\hline$\%$ & ك & $\%$ & (5) & $\overline{\%}$ & (5 & $\%$ & (5 & $\%$ & ك5 & $\%$ & (5) & & \\
\hline$\overline{0}$ & $i$ & $\therefore$ & 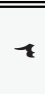 & $\xi$ & - & $\stackrel{?}{0}$ & $>$ & $\begin{array}{l}1 \\
\\
0 \\
0\end{array}$ & z & $\overline{1}$ & m & 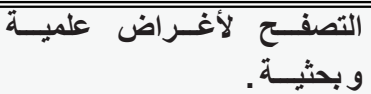 & 1 \\
\hline : & $\underline{z}$ & $\begin{array}{l}5 \\
\\
0\end{array}$ & 4 & $\ddot{z}$ & on & $\begin{array}{l}3 \\
2 \\
\vdots \\
0\end{array}$ & + & 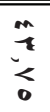 & $\approx$ & $\begin{array}{l}3 \\
2 \\
\vdots \\
0\end{array}$ & + & التواصل مع مواقع الجامعات. & $r$ \\
\hline 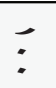 & 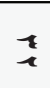 & $\begin{array}{c}5 \\
0 \\
0\end{array}$ & 4 & 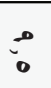 & 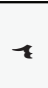 & $?$ & ـ & $\ddot{m}$ & $\overline{7}$ & $\because$ & - & نشر نشاطات الجامعة الكترونيا. & $r$ \\
\hline$\vdots$ & $i$ & $\stackrel{0}{0}$ & 7 & $\frac{\pi}{1}$ & $a$ & $\stackrel{3}{?}$ & مـ & $\begin{array}{l}m \\
\vdots \\
0 \\
0\end{array}$ & - & 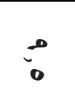 & 7 & 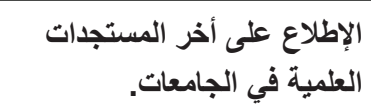 & $\varepsilon$ \\
\hline$\vdots$ & 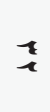 & 5 & 1 & $\begin{array}{l}\sum_{2} \\
\vdots \\
0\end{array}$ & $I$ & $\because$ & $>$ & $\begin{array}{l}1 \\
5 \\
1 \\
0\end{array}$ & 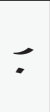 & $\begin{array}{l}\sum_{3} \\
\text { s } \\
0\end{array}$ & $\Rightarrow$ & 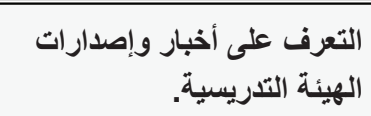 & 。 \\
\hline : & $i$ & $\therefore$ & 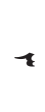 & $\vec{a}$ & m & $\begin{array}{l}5 \\
\vdots \\
\vdots \\
0\end{array}$ & a & $\begin{array}{l}1 \\
m \\
0 \\
0\end{array}$ & $=$ & $\because$ & $>$ & بالعملية التعليمية. & 9 \\
\hline ? & $i$ & $\frac{a}{1}$ & 4 & $\because$ & 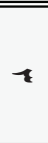 & $\because$ & $>$ & $\underset{0}{1}$ & z & $\begin{array}{l}1 \\
\vdots \\
0\end{array}$ & $<$ & اللاسورات العلمية التي تقيمهات والترويج & $\mathrm{V}$ \\
\hline : & 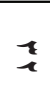 & $\begin{array}{l}5 \\
5 \\
0\end{array}$ & 1 & $\because$ & $\bullet$ & $?$ & مـ & $\begin{array}{l}1 \\
m \\
0 \\
0\end{array}$ & $=$ & $\because$ & - & الجامعة محلياً وعربياً إبراز فعاليات & $\wedge$ \\
\hline
\end{tabular}

المحسور الرابـع: الهـدف مـن اســخدام العلاقـات العامــة الرقميـة في الجامعـات العراقيـة كانـت إجابـات المبحوثيـن ضمن المحـور الرابع أي الهــف من اســخدام العلاقات العامة 
الرقميـة فـي الجامعـات العراقية هو حصول مقيـاس (أتفق) كترتيب اول مـن المحور أعلاه ثم

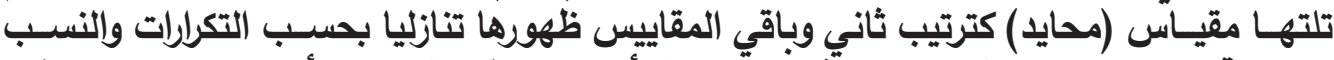

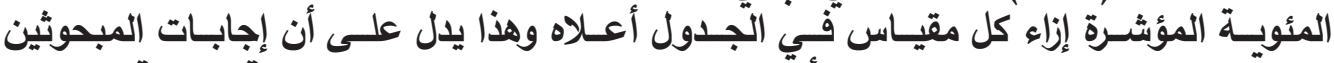

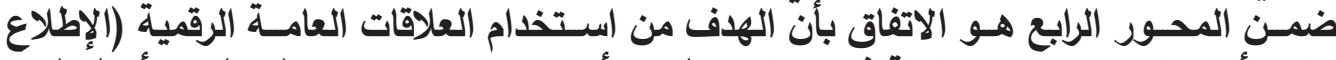

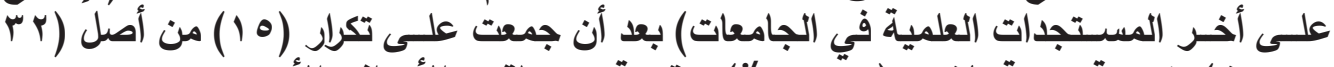

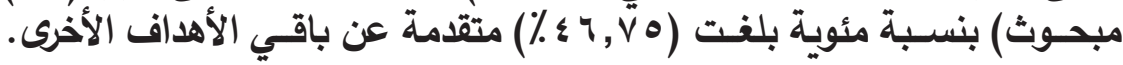

جـول (11) يبين إسـتراتيجيات الاتصال للعلاقات العامـة الرقمية في الجامعات العراقية

\begin{tabular}{|c|c|c|c|c|c|c|c|c|c|c|c|c|c|}
\hline \multicolumn{2}{|c|}{ المجموع } & \multicolumn{2}{|c|}{ لا أتفق } & \multicolumn{2}{|c|}{ لا أتفق } & \multicolumn{2}{|c|}{ محايد } & \multicolumn{2}{|c|}{ اتفق } & \multicolumn{2}{|c|}{ بثدة } & \multirow[t]{2}{*}{ نوع الفقرة } & \multirow[t]{2}{*}{$ت$} \\
\hline$\%$ & ك5 & $\%$ & ك5 & $\%$ & ك5 & $\%$ & ك & $\%$ & S5 & $\%$ & ك & & \\
\hline : & 1 & $\square_{0}^{\circ}$ & 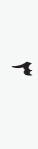 & $\begin{array}{l}m \\
\vdots \\
< \\
0\end{array}$ & $\overline{0}$ & $\begin{array}{l}1 \\
\vdots \\
0\end{array}$ & $<$ & $\begin{array}{l}0 \\
0 \\
\vdots \\
0\end{array}$ & - & $\begin{array}{l}5 \\
1 \\
0\end{array}$ & 4 & 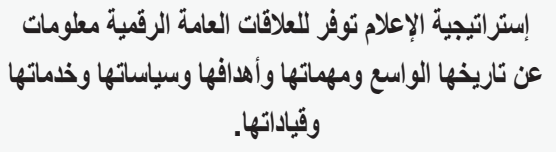 & 1 \\
\hline : & 1 & 5 & 1 & $\because$ & F & $\because$ & $>$ & $\begin{array}{l}> \\
< \\
0\end{array}$ & - & ○ & 1 & 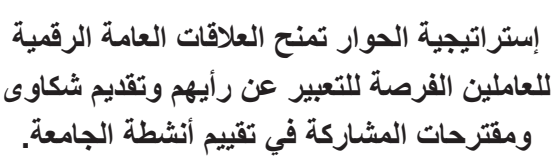 & $r$ \\
\hline ? & 1 & $\begin{array}{l}a \\
a \\
0\end{array}$ & m & $\begin{array}{l}1 \\
0 \\
1 \\
0\end{array}$ & ? & $\begin{array}{l}3 \\
< \\
0\end{array}$ & - & $\begin{array}{l}1 \\
0 \\
0\end{array}$ & $<$ & $\begin{array}{l}0 \\
0 \\
0 \\
0\end{array}$ & - & 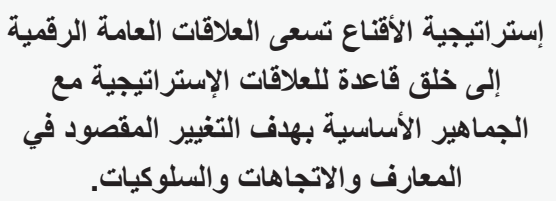 & $r$ \\
\hline : & 1 & $\because$ & 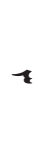 & $\begin{array}{l}1 \\
z \\
1 \\
0\end{array}$ & z & : & $>$ & $\begin{array}{l}0 \\
\vdots \\
0\end{array}$ & 0 & $\tilde{a}$ & $m$ & الرقية لبناء علاقات إستراتيجية الإجماع تعتمد العلاقات العامينة الجامعة وبيئتها & $\varepsilon$ \\
\hline
\end{tabular}

\begin{tabular}{c|c} 
& مجلة الباحث الإعلامي \\
\hline$\Lambda 4$ & (rv (rva
\end{tabular} 
المحور الخامس : إستراتيجيات الاتصال للعلاقات العامة الرقمية في الجامعات العراقية أظهرت نتائسج إجابـات المبحوثين على المحور الخامس تقدم مقيساس (لا أتفق) عن باقي

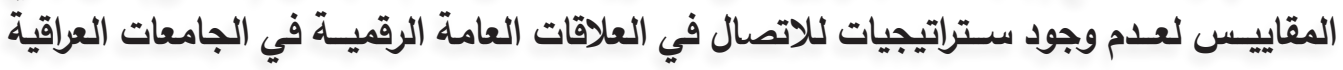

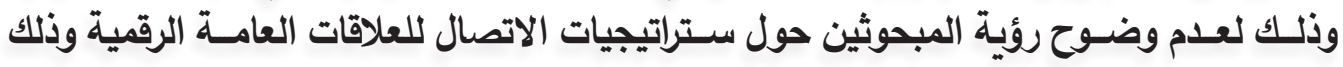

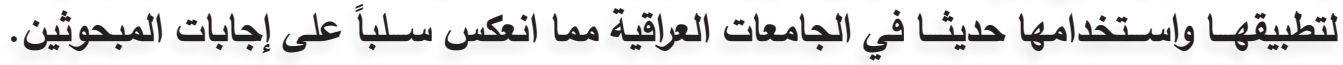
جدول (Y I) يبيـن الصعوبات التي تعيق عمل العلاقات العامـة الرقمية في الجامعات العراقية

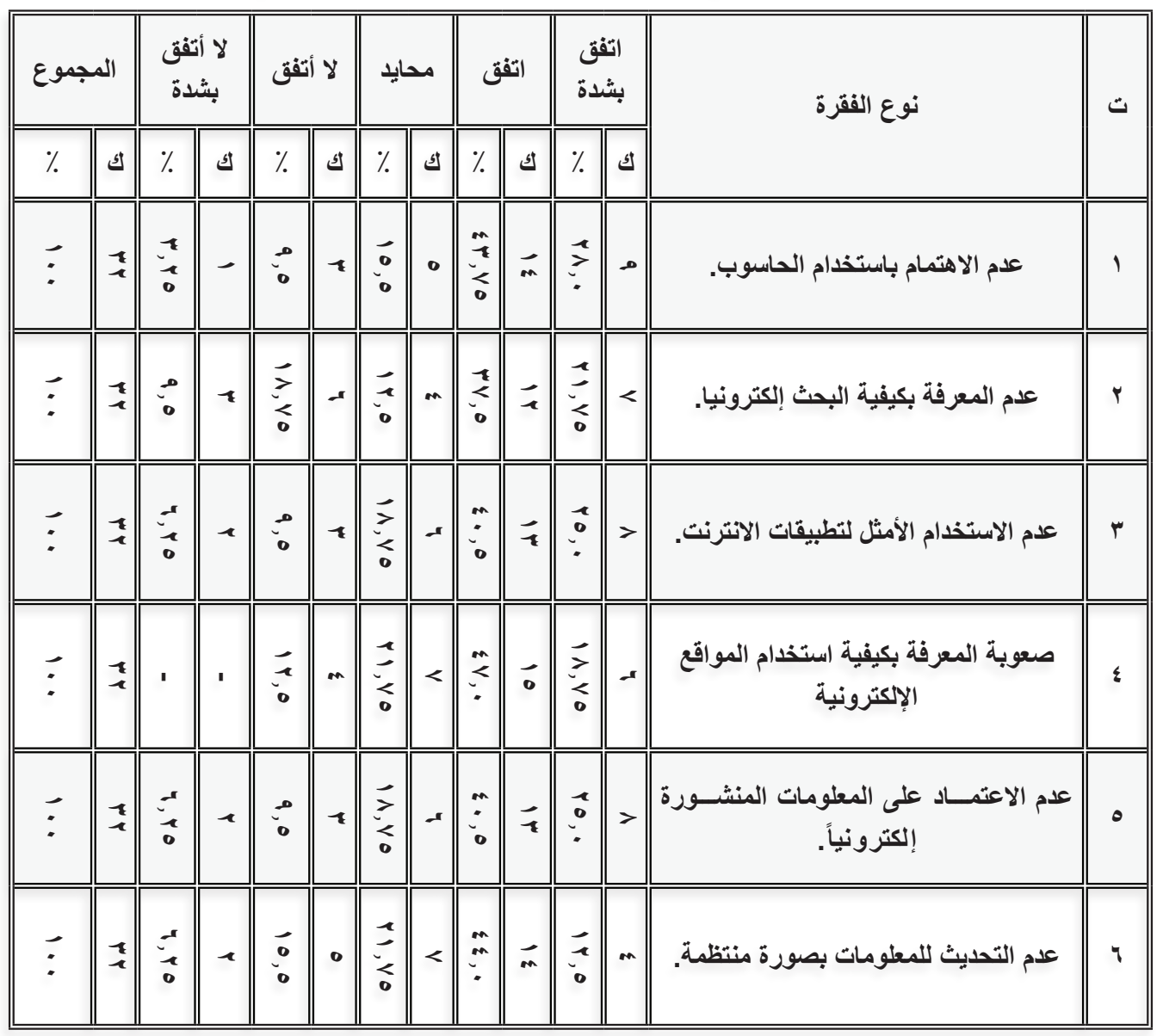


المحور السادس : الصعوبات التي تعيق عمل العلاقات العامة الرقمية في الجامعات العراقية

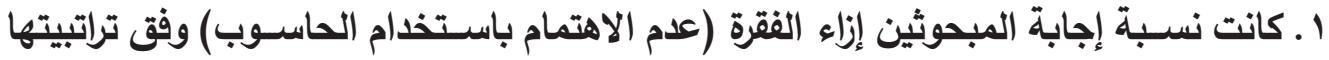

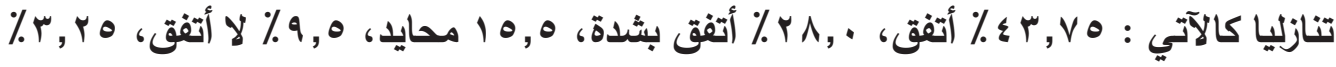

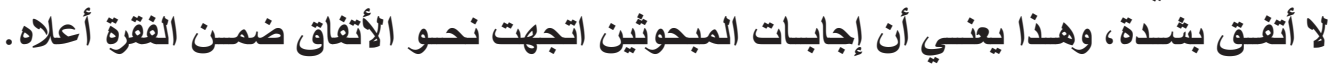
r ـ كانـت نسـبة إجابـات المبحوثين إزاء الفقـرة (عدم المعرفة بكيفية البحـث إلكترونيا) كالآتي

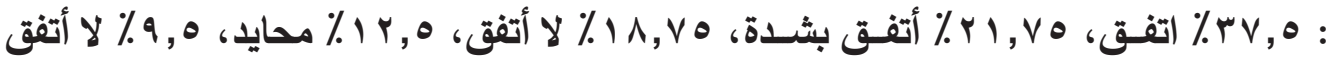

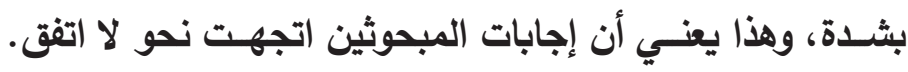

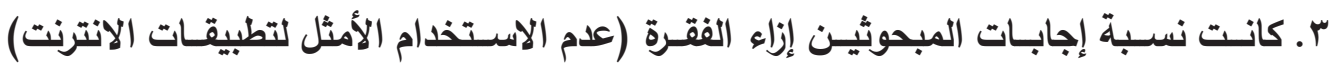

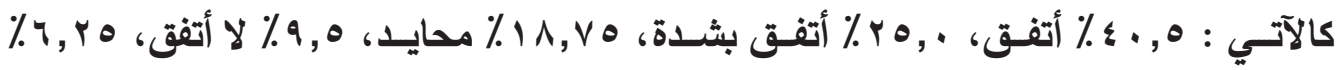

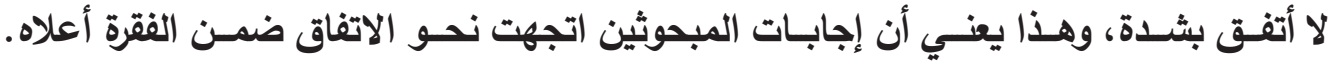

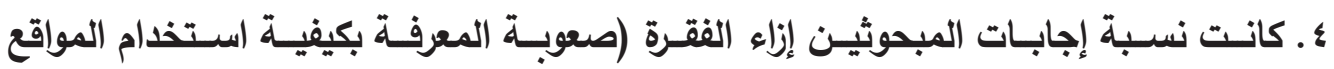

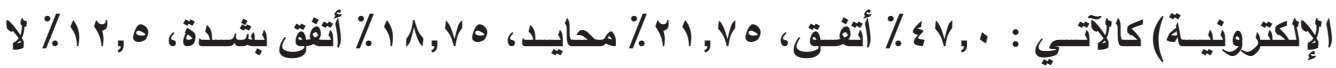

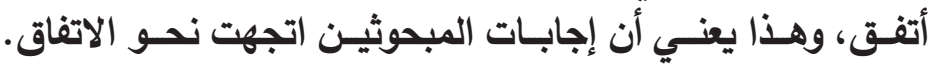

هـ كانـت نسـبة إجابـات المبحوثين إزاء الفقرة (عدم الاعتماد بالمعلومات المنشـورة إلكترونياً)

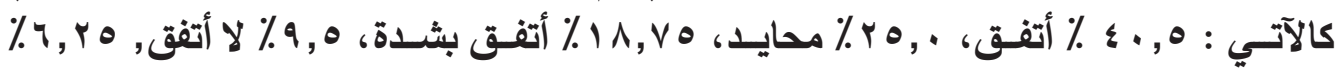

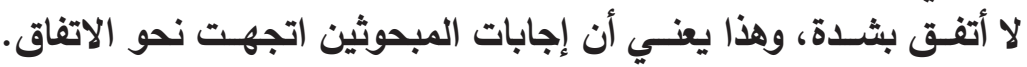

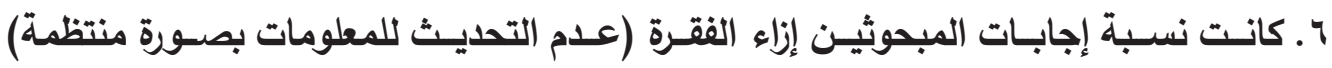

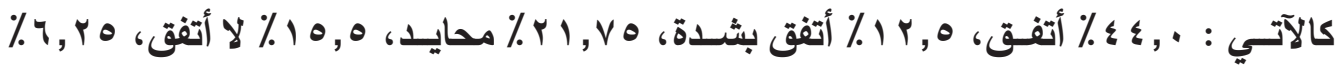

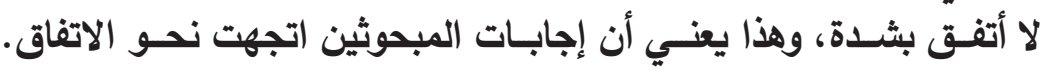

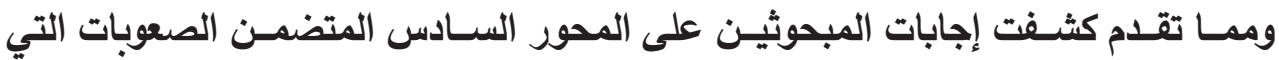

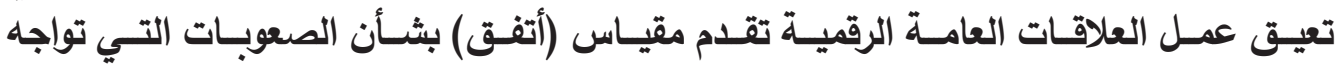

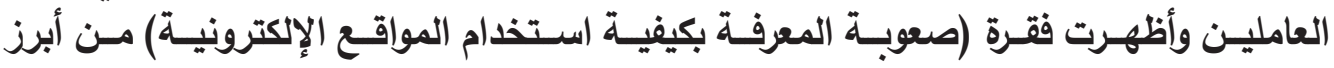

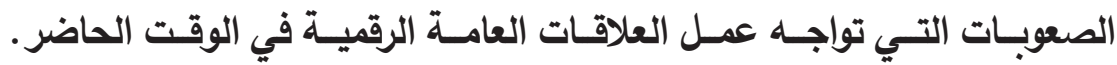

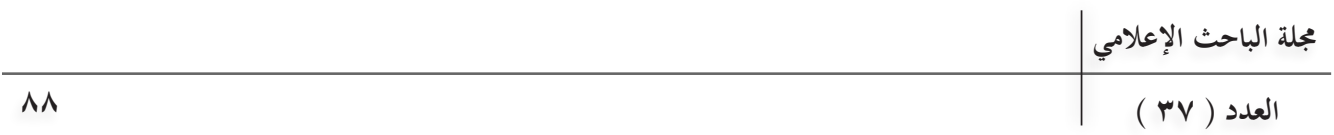




\section{الاستنتاجات}

ا ـ جاءت نسـبة مشـاركة المبحوثين تقدم الأكور على الإناث، أما بثـأن المسـتويات

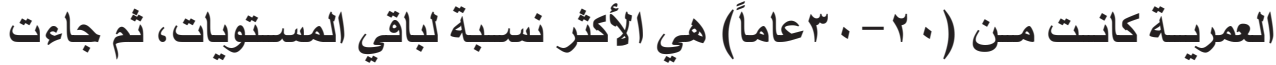

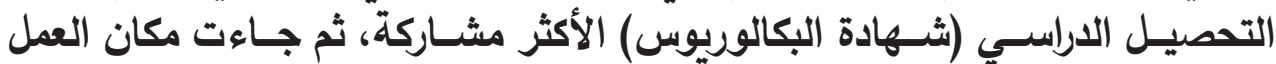

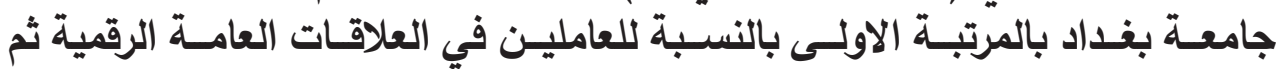

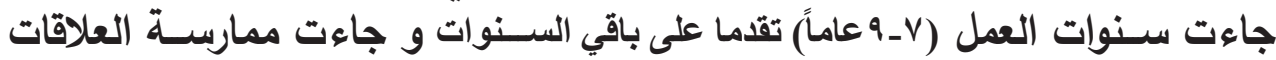
العامـة الرقميـة فـي الجامعـات العراقية ضمن تصنيـف متغير (نعـم) بالمرتبة الاولى. r ـ . كثفت الدراسة المسحية للعاملين في العلاقات العامة الرقميةفي الجامعات العراقيةنسب متقاربة العابة

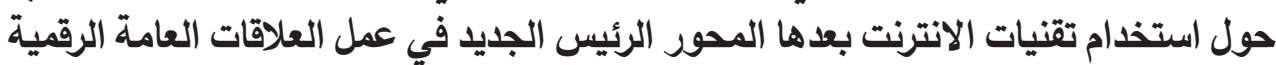
بينما كانت الإجابة الأضعف هي عدم استخدام تقنيات الانترنت في مجال العلاقات العات العامة.

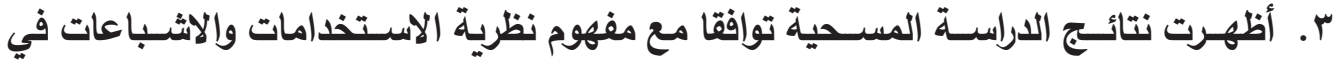

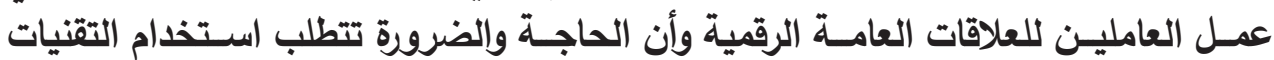

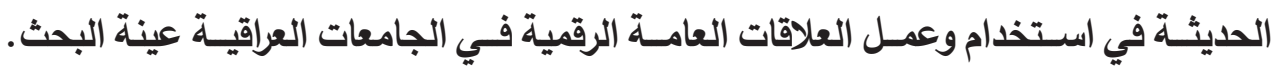

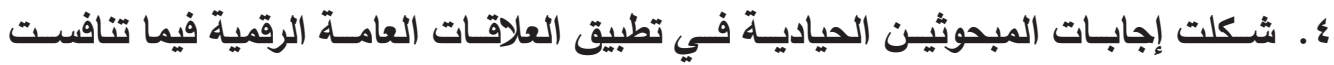

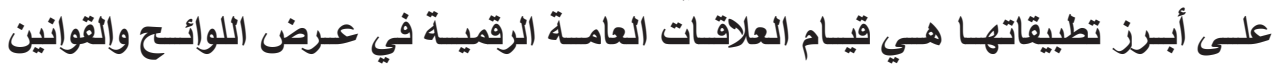

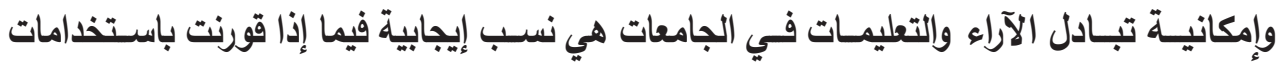
العامليـن للعلاقـات العامـة الرقمية.

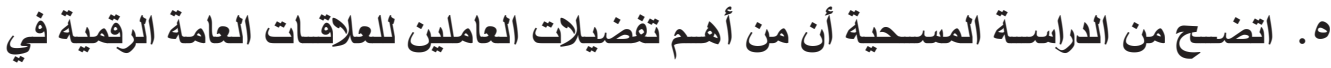

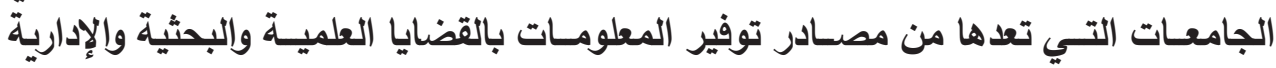
في الجامعات العراقية.

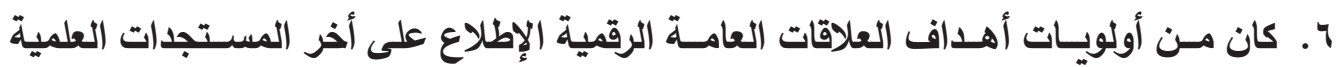

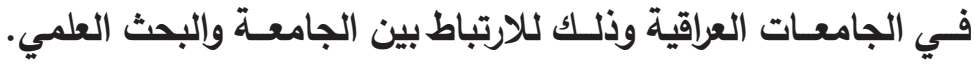

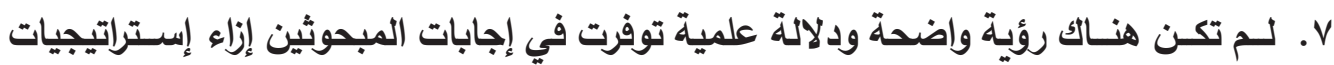

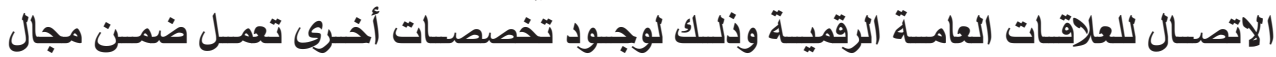
العلاقات العامــة الرقمية.

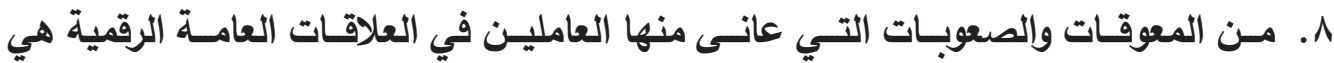

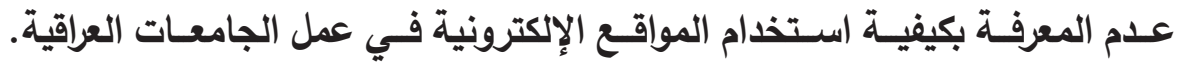

\begin{tabular}{l|c} 
& العلة الباحث الإعلامي \\
\hline 19 & (rv (rv (r)
\end{tabular}




\section{الهوامش و المصادر}

ا ـ محمد عبد الحميد، البحث العلمي في الاراسات الإعلامية، (القاهرة : عالم الكتب، . . . ץ)، ص • V.

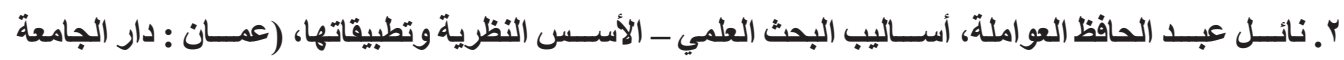

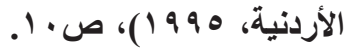

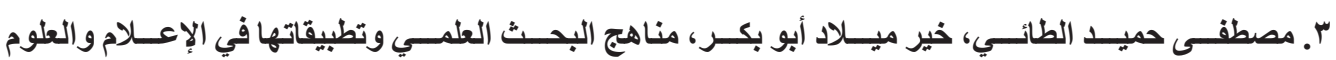

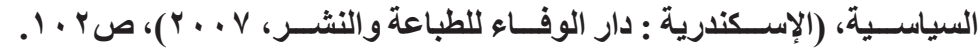

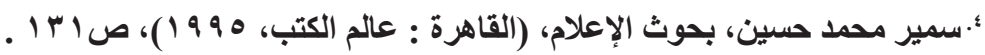

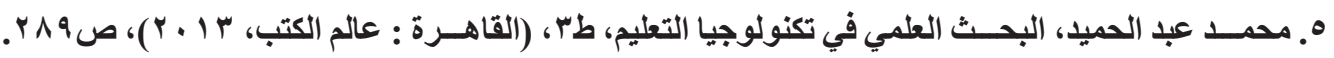
4. عبـــ الخالــق محمد شــفيق , العلاقات العامة في الخدمــة الاجتماعية , ( القاهرة , المكتبة العصرية للنشــر

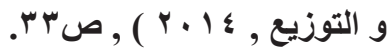
ـ أيــاد حســن الرمضاني وآخرون، المدخل إلى الثــبكة التبادلية والبريد الإكترّونـي، (الموصل : دار جامعة

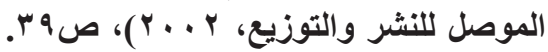

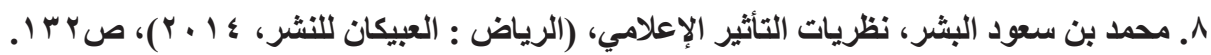

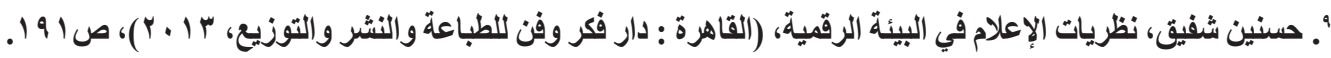

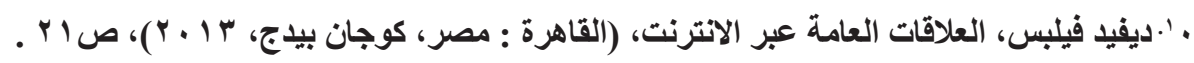

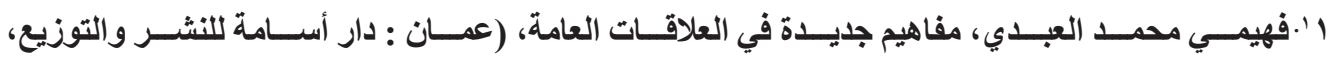

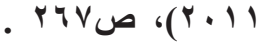

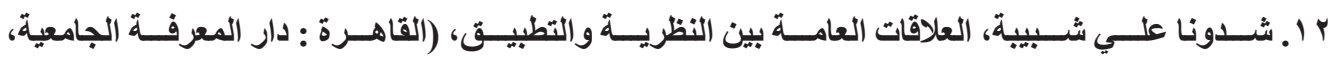
(r...q

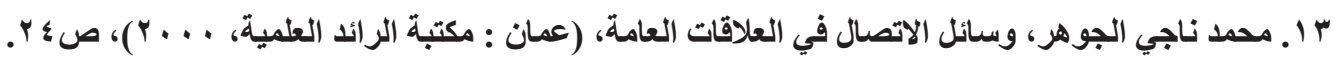

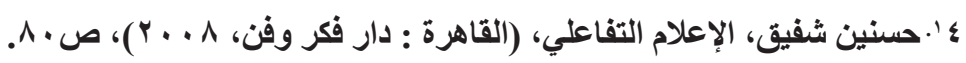

Barbee, Daviel E, interactive Multimedia - information Resources management .'

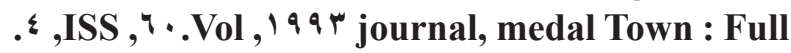
7 ا ـ محمد ناجي الجوهر، وسائل الاتصال في العلاقات العامة، مصدر سبق ذكره، صه ب . . ال ا محمـــ ناجي الجوهر، المــواد الإعلامية التقليليــة والإكترونية في العلاقات العامــة، (اليمن، دار الكتاب

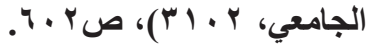

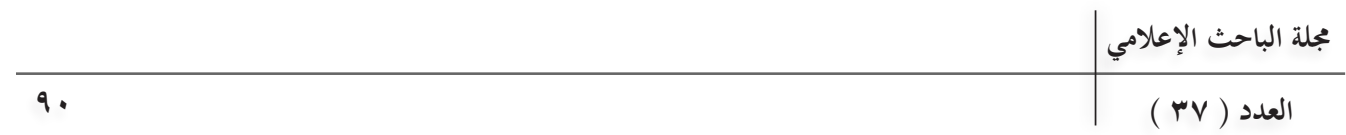

